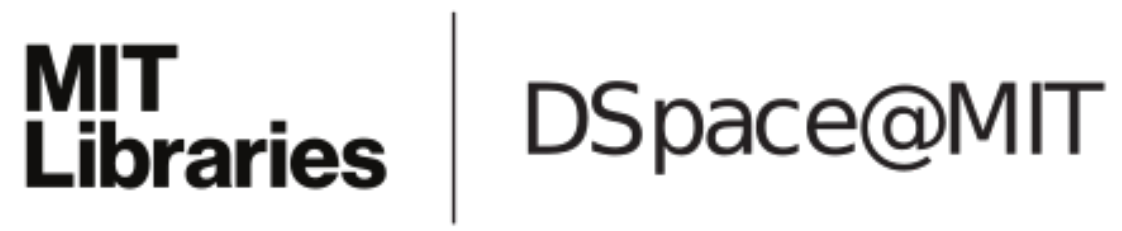

\author{
MIT Open Access Articles
}

Trivalent phosphorus and phosphines as components of biochemistry in anoxic environments

The MIT Faculty has made this article openly available. Please share how this access benefits you. Your story matters.

Citation: Bains, William, Janusz Petkowski, Clara Sousa-Silva, and Sara Seager, "Trivalent phosphorus and phosphines as components of biochemistry in anoxic environments." Astrobiology 19, 7 (July 2019): p. 885-902 doi 10.1089/AST.2018.1958 @2019 Author(s)

As Published: 10.1089/AST.2018.1958

Publisher: Mary Ann Liebert Inc

Persistent URL: https://hdl.handle.net/1721.1/124611

Version: Final published version: final published article, as it appeared in a journal, conference proceedings, or other formally published context

Terms of Use: Article is made available in accordance with the publisher's policy and may be subject to US copyright law. Please refer to the publisher's site for terms of use. 


\title{
Trivalent Phosphorus and Phosphines as Components of Biochemistry in Anoxic Environments
}

\author{
William Bains, ${ }^{1}$ Janusz Jurand Petkowski, ${ }^{2}$ Clara Sousa-Silva, ${ }^{2}$ and Sara Seager ${ }^{2-4}$
}

\begin{abstract}
Phosphorus is an essential element for all life on Earth, yet trivalent phosphorus (e.g., in phosphines) appears to be almost completely absent from biology. Instead phosphorus is utilized by life almost exclusively as phosphate, apart from a small contingent of other pentavalent phosphorus compounds containing structurally similar chemical groups. In this work, we address four previously stated arguments as to why life does not explore trivalent phosphorus: (1) precedent (lack of confirmed instances of trivalent phosphorus in biochemicals suggests that life does not have the means to exploit this chemistry), (2) thermodynamic limitations (synthesizing trivalent phosphorus compounds is too energetically costly), (3) stability (phosphines are too reactive and readily oxidize in an oxygen $\left(\mathrm{O}_{2}\right)$-rich atmosphere), and (4) toxicity (the trivalent phosphorus compounds are broadly toxic). We argue that the first two of these arguments are invalid, and the third and fourth arguments only apply to the $\mathrm{O}_{2}$-rich environment of modern Earth. Specifically, both the reactivity and toxicity of phosphines are specific to aerobic life and strictly dependent on $\mathrm{O}_{2}$-rich environment. We postulate that anaerobic life persisting in anoxic $\left(\mathrm{O}_{2}\right.$-free) environments may exploit trivalent phosphorus chemistry much more extensively. We review the production of trivalent phosphorus compounds by anaerobic organisms, including phosphine gas and an alkyl phosphine, phospholane. We suggest that the failure to find more such compounds in modern terrestrial life may be a result of the strong bias of the search for natural products toward aerobic organisms. We postulate that a more thorough identification of metabolites of the anaerobic biosphere could reveal many more trivalent phosphorus compounds. We conclude with a discussion of the implications of our work for the origin and early evolution of life, and suggest that trivalent phosphorus compounds could be valuable markers for both extraterrestrial life and the Shadow Biosphere on Earth. Key Words: PhosphineChemical space-Shadow Biosphere-Anaerobes-Archean Earth-Anoxic exoplanets. Astrobiology 19, 885-902.
\end{abstract}

\section{Introduction: Trivalent Phosphorus and Life}

$\mathbf{T}$ HE CHEMISTRY OF LIFE does not use all the chemical possibilities inherent in the major elements that make up biochemistry. There are some unexpected "gaps" in the coverage of stable chemical space by the chemistry of life (Petkowski et al., 2019a). Explaining why life does not use chemistry in these "gaps" can be as important as explaining why life does exploit the atom, bond, and molecule classes commonly found in biochemistry. Such explanations illuminate the chemical nature and evolution of life on Earth, and address whether profoundly different chemistry could be the basis of life on other worlds.

An example of such avoided areas of chemical space is the relative absence in biochemistry of bonds between ni- trogen and sulfur atoms (N-S bonds). N-S chemistry is stable, flexible, provides wide reactivity, and structural and redox functionality to molecules. $\mathrm{N}-\mathrm{S}$ chemistry is extensively exploited in human chemical technology, and yet is only found in $0.05 \%$ of small molecules made by life (Petkowski et al., 2018). One reason for this extreme scarcity can be traced to the reactivity of large subset of N-S chemicals to thiols (Petkowski et al., 2019a), therefore rendering $\mathrm{N}-\mathrm{S}$ bond chemistry incompatible with thiols, which are an essential component of the chemistry of the cell. We have speculated that the existence of such avoided areas of chemical space is a specific example of a more general phenomenon: the chemistry that life can use is limited not only by obvious environmental constraints (such as stability to hydrolysis or availability of elements) but also

\footnotetext{
${ }^{1}$ Rufus Scientific, Royston, United Kingdom.

Departments of ${ }^{2}$ Earth, Atmospheric, and Planetary Sciences, ${ }^{3}$ Physics, and ${ }^{4}$ Aeronautics and Astronautics, Massachusetts Institute of Technology, Cambridge, Massachusetts.
} 


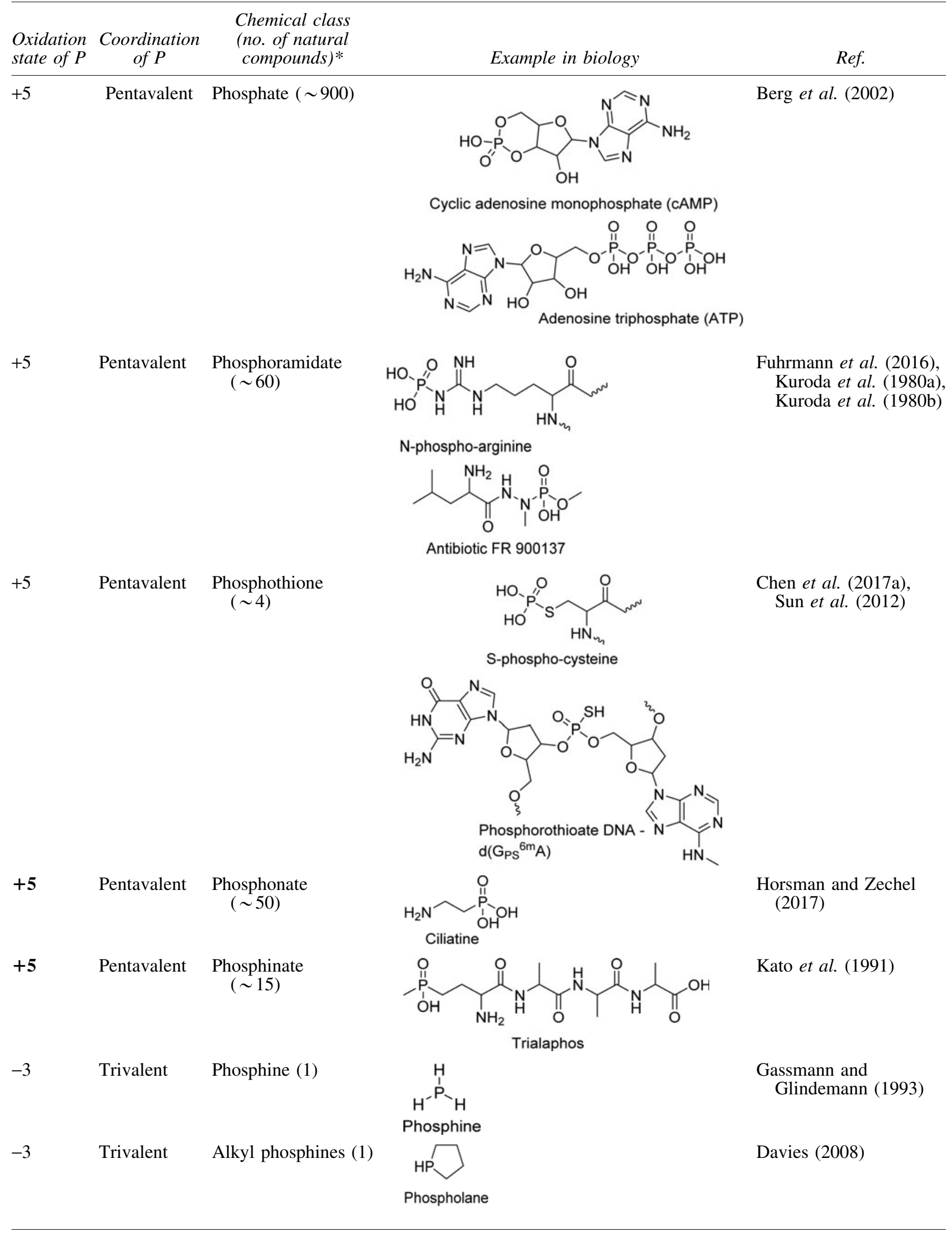

The great majority of pentavalent phosphorus-containing natural compounds are phosphates (Petkowski et al., 2019b). The trivalent phosphorus compounds appear to be almost completely absent from biology. *Polymers of life (e.g., DNA, RNA, or proteins) are represented as their respective monomers. 
by a range of more subtle constraints on how a self-consistent biochemistry can be assembled (Petkowski et al., 2019a).

In this article, we present another example of such a limitation, which is the degree of utilization of phosphorus chemistry by life. Phosphorus is an essential element of all life, and it is used in all the major components of biochemistry (e.g., in nucleic acids, proteins, carbohydrate metabolism, and lipids). However, almost all of life's use of phosphorus is as phosphorus in the +5 oxidation state, and almost all of the phosphorus-containing compounds that are made by life are phosphates. Other phosphorus compounds that link phosphorus with five covalent bonds (hereafter pentavalent phosphorus ${ }^{1}$ ) to nitrogen, sulfur, or carbon atoms are known in some natural products, but are rare: only $\sim 130$ compounds are known, which contain phosphorus atoms that are not in a phosphate group (see Petkowski et al. (2019a) for descriptions of the databases used to draw these conclusions; for the recent review on the utilization of the rare organophosphorus funtional groups by life on Earth, see Petkowski et al., 2019b). The structural similarity between these compounds is clear (Table 1). By contrast, phosphorus with only three covalent bonds (hereafter trivalent phosphorus) is almost unknown in biochemistry (Table 1).

Life's apparent lack of the use of trivalent phosphorus is interesting, as an example of a type of chemistry not used by life, for two reasons:

First, all the other major elements used by life $(\mathrm{C}, \mathrm{H}, \mathrm{N}$, $\mathrm{O}$, and $\mathrm{S}$ ) are used in a wide range of chemical contexts, for example, sulfur is used in 2-, 4-, and 6-coordinate compounds, and in all oxidation states from -2 to +6 (reviewed in Nagy and Winterbourn, 2010). By contrast, life appears not to use the available chemical versatility of phosphorus beyond the pentavalent phosphorus in the +5 oxidation state.

Second, the trivalent phosphorus chemistry, and specifically the chemistry of substituted phosphines, is widely used by humans in synthetic and catalytic chemistry, illustrating its versatility and utility (reviewed in Clarke and Williams, 2004; Allen, 2012) and is particularly valuable for tuning the steric and electronic properties of metals (Buono et al., 2008; Kamer and van Leeuwen, 2012). Its apparent avoidance by life therefore deprives biochemistry of useful chemical functionality.

In this article, we summarize and discuss four reasons that can be given for dismissing trivalent phosphorus compounds as plausible biochemicals.

1. Precedent. The first reason for implausibility of trivalent phosphorus in biochemistry comes from a recurring notion that no such compounds are made by life (Section 2).

\footnotetext{
${ }^{1}$ We remind the reader of the distinction between bonding, coordination number, and oxidation state. Phosphorus in phosphate is usually designated $\mathrm{P}(\mathrm{V})$ : it has a +5 oxidation state and five covalent bonds to oxygen atoms. Its coordination number is 4 , as the central phosphorus atom is surrounded by four other atoms. However, identifying phosphorus in phosphate as $\mathrm{P}(\mathrm{V})$ is ambiguous. Phosphorus in phosphite has five covalent bonds (and coordination number of 4 ), but $\mathrm{a}+3$ oxidation state, as hydrogen is more electropositive than phosphorus. Phosphorus in diphosphine has three covalent bonds but an oxidation state of -2 . In this article, we classify compounds by their structure and discuss the oxidation state of those structures only in the context of the energy needed to make them.
}

2. Thermodynamics. The second reason comes from the thermodynamic demands of synthesis of trivalent phosphorus compounds. Phosphorus is present in the crust and ocean primarily as phosphate, with small amounts of the +3 oxidation state pentavalent ion phosphite in some marine and lacustrine environments (Han et al., 2012; Yu et al., 2015; Figueroa and Coates, 2017). These compounds all contain the $\mathrm{P}=\mathrm{O}$ group. Substantial energy would be needed to reduce this group, so as to form any trivalent phosphorus compound. The common understanding is that the thermodynamic barrier to the formation of trivalent phosphorus makes its chemistry, and in particular the chemistry of phosphine, unattractive compared with other chemistries that could provide similar functionality (Section 3).

3. Stability. The third possible reason for the exclusion of trivalent phosphorus chemistry from biochemistry comes from its reactivity. Specifically, these compounds are rapidly and irreversibly oxidized to their oxides by atmospheric oxygen $\left(\mathrm{O}_{2}\right)$. Indeed, substituted phosphines are widely used as reducing agents in chemistry precisely because of their fast reaction and high electrode potential (Clarke and Williams, 2004). As a result, any phosphine that life would make would be a short-lived species in modern terrestrial, $\mathrm{O}_{2}$-rich surface environment (Section 4).

4. Toxicity. Finally, the toxicity of phosphine, and of related compounds, could also contribute to the exclusion of trivalent phosphorus from biochemistry (Section 5).

In this article, we argue that the first and second of these arguments cannot sufficiently explain the scarcity of trivalent phosphorus in biochemistry (Sections 2 and 3). As for the latter two arguments, while they are valid and powerful explanations for why life on the surface of the modern Earth does not produce trivalent phosphorus compounds, they do not apply to an anoxic (lacking oxygen) reducing environment (Sections 4 and 5). We conclude by discussing possible environments and conditions in which trivalent phosphorus chemistry could be much more extensively exploited by life, namely in highly anoxic environments on or below the surface of modern Earth, on the Archean Earth, and on exoplanets with nonoxidizing atmospheres (Section 6). Our work has implications for the chemistry of early life on Earth, for the nature of life in a potential "Shadow Biosphere," and the search for life on exoplanets, especially those with reducing anoxic surface environments (Section 6).

\section{The Extent of Production of Trivalent Phosphorus Compounds by Life on Earth}

In this section, we review the extensive evidence that life on Earth makes phosphine gas $\left(\mathrm{PH}_{3}\right)$, the simplest trivalent phosphorus compound, and discuss the evidence that at least some of the phosphine production could be the result of energy capture reactions (Section 2.1). We also explore the possibility that there may be other trivalent phosphorus compounds made by life waiting to be discovered. We discuss one known example of such natural alkyl phosphine (Section 2.2). Thus, the apparent precedent for the scarcity 
of trivalent phosphorus compounds in biochemistry cannot be used as a compelling explanation for their exclusion by life.

\subsection{Phosphine production by life is strictly dependent on an anaerobic environment}

Phosphine is a reactive, pungent, and irritating gas (Ruth, 1986). It is a trace component in the atmosphere on modern Earth, present in low ppb to low ppt levels, depending on location (Morton and Edwards, 2005). About 10\% of the phosphorus in the atmosphere is phosphine, while the major form of atmospheric phosphorus is phosphate (Elm et al., 2017).

On modern Earth, human industrial activity is a source of phosphine. This includes phosphine generated by phosphide rodenticides and insecticides (Devai et al., 1988; Han et al., 2000; Roels and Verstraete, 2001; Glindemann et al., 2005; Chen et al., 2017b), and phosphine itself, which is used for commercial purposes such as a doping agent (Budavari et al., 1996). Some countries with intense agricultural industries, for example, China, have relatively high levels of ambient anthropogenic phosphine (Cao et al., 2000).

The majority of atmospheric phosphine is believed to be associated with biological activity (Glindemann et al., 2005; Morton and Edwards, 2005). There are three possible explanations for the association of phosphine production on Earth with anoxic biology [extensively reviewed elsewhere (Glindemann et al., 1998; Roels and Verstraete, 2001, 2004; Roels et al., 2005; Bains et al., 2019)]. First, that living organisms produce phosphine directly from phosphate; second, that organisms make phosphine by disproportionation of phosphite; and third, that phosphine is made indirectly by biologically driven acid corrosion of environmental phosphide.

Phosphine production is associated with biological activity in a wide range of environments that are strictly anoxic (Devai et al., 1988; Glindemann et al., 1996). These environments include rivers and lakes (whose bottom sediments are anoxic) (Gassmann and Glindemann, 1993; Feng et al., 2008a, 2008b; Han et al., 2011a, 2011b), biogas and landfill gas that is generated by the anaerobic decomposition of domestic waste (Roels and Verstraete, 2004; Ding et al., 2005), and a range of wetland and marshland soils (Devai and Delaune, 1995; Eismann et al., 1997; Han et al., 2000; Chen et al., 2017b). All of these are complex anaerobic environments with phosphate available as dissolved phosphate or as phosphate-containing organic chemicals.

Phosphine (as well as other reduced phosphorus species such as phosphite) is also detected in feces and flatus from many animals, including termites (Pech et al., 2011), penguins (Zhu et al., 2006, 2014), cattle and pigs (Glindemann et al., 2005), and humans (Chughtai and Pridham, 1998). Guts are typically completely anaerobic, with anaerobic bacteria outnumbering aerobic bacteria (see, e.g., Sissons, 1989; Cahill, 1990; Guarner and Malagelada, 2003), even in guts as small as those of earthworms (Schmidt et al., 2011) or termites (Brune et al., 1995). We would not expect animal guts to contain metals or phosphide-containing minerals, so phosphine in animal guts is probably generated from soluble phosphorus species such as phosphate or from phosphate-containing organic chemicals by direct biological action.
Finally, several studies have reported the production of phosphine from mixed bacterial cultures in a laboratory setting. Reduced phosphorus species have been associated with microbial attack on metals in laboratory experiments, especially steel, for more than 50 years (Iverson, 1968, 1974). Production of $\mathrm{PH}_{3}$ itself has been reported by several studies (Rutishauser and Bachofen, 1999; Jenkins et al., 2000), in one case bacteria turning half the phosphorus in a culture medium $(\sim 180 \mathrm{mg} / \mathrm{L})$ into phosphine over a period of 56 days (Devai et al., 1988). It is important to note that the laboratory culture experiments that report the production of phosphine are performed in a controlled manner and using materials and media likely to contain very low levels of metals or phosphide, making the indirect acid-dependent production of phosphine from attack on metals or phosphide an unlikely scenario. It is therefore more probable, just as it is in the case of phosphine production in animal guts, that phosphine is generated from soluble phosphorus species by a direct biological action. Nonetheless, the detailed biosynthetic pathway for microbial phosphine production is currently unknown.

Thus, the evidence that phosphine is made by living organisms is strong. We address the thermodynamic issues of phosphine synthesis in Section 3.

\subsection{Production of trivalent compounds other than phosphine}

Two lines of evidence suggest that molecules containing trivalent phosphorus are very rarely made by life.

A thorough compilation of all the compounds produced by life that have been structurally characterized (Petkowski et al., 2019a) identified only one compound containing trivalent phosphorus other than phosphine itself. This compound is a cyclic alkyl phosphine called phospholane (Table 1), found in European badger feces (Davies, 2008). The detection of phospholane was carefully validated, as it was found in separate samples from both wild and captive populations, and so is unlikely to be either an artifact or a breakdown product of an industrial contaminant. However, the biosynthetic route and biological function of phospholane remain unknown. As discussed above, feces are a highly anaerobic environment, one in which $\mathrm{PH}_{3}$ itself was detected (Section 2.1). The detection of phospholane further supports the association of trivalent phosphorus metabolism with strictly anoxic environments.

The second line of evidence is the failure to detect trivalent phosphorus compounds in biological samples using phosphorus nuclear magnetic resonance (NMR). ${ }^{31} \mathrm{P}$ NMR is widely used in biochemical research to detect and characterize phosphorus species (Lane, 2012). Phosphine and alkyl-substituted phosphines have large negative chemical shifts compared with phosphates (Gorenstein, 1984), and would give very distinctive NMR signals. Phospholanes, for example, have a negative shift in excess of $60 \mathrm{ppm}$ compared with phosphate (Brunner and Sievi, 1987), while the typical NMR shifts used to distinguish the phosphate groups in phospholipids from each other (Glonek, 1994) or to distinguish nucleotides in oligonucleotides (Gorenstein, 1994) are in the order of 1 to $2 \mathrm{ppm}$. Multidimensional NMR techniques can add further resolution to the NMR signal (Lane, 2012). However, signals of any natural trivalent phosphorus 
compounds have so far not been reported. ${ }^{31} \mathrm{P}$ NMR can detect substances present at $<1 \%$ of the level of the major phosphorus-containing substances in a sample (Glonek, 1994), which suggests that trivalent phosphorus is present at $<1 \%$ of the level of compounds such as phosphatidylcholine or adenosine triphosphate (ATP). However, we note that all the NMR studies on metabolites that we have found have been on aerobic organisms (mostly mammals, higher plants, or yeast).

Could there be other biological trivalent phosphorus compounds awaiting discovery? We believe there could be, despite the paucity of such compounds reported in databases and literature of "natural products" (i.e., chemicals made by life), and the lack of detection of such compounds by NMR metabolomic surveys. Databases of natural products are inconsistent on how they report the source sample from which a chemical is derived, so the degree to which collections are biased toward aerobic environments is not known. However, it is clear that the large majority of natural products are identified from aerobic samples-plants, animals, soil fungi, ascomycetes grown in aerated culture, and marine organisms (Fig. 1). Very few are collected from anaerobic samples, and indeed, received wisdom among natural product chemists has been that anaerobic organisms do not produce secondary metabolites (Behnken and Hertweck, 2012). Metabolomic surveys also focus, almost exclusively,

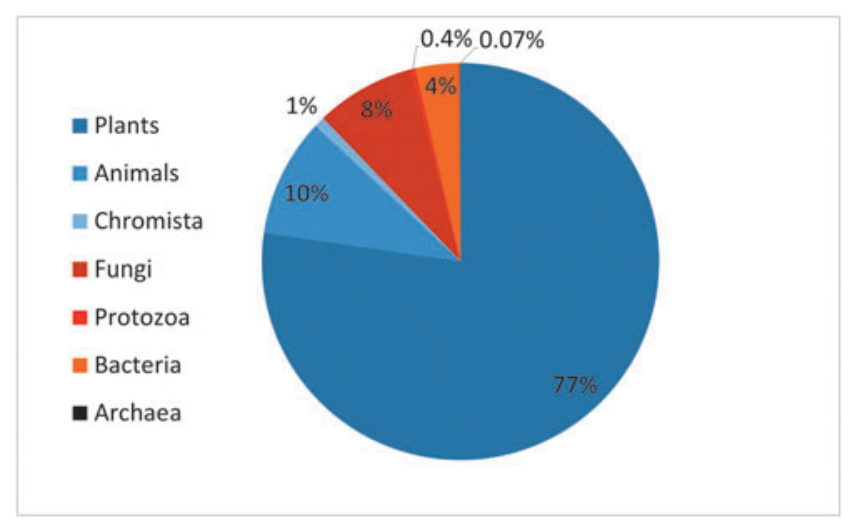

FIG. 1. The distribution of source organisms of known natural products shows a strong bias of the search for natural compounds toward aerobic organisms. At least $88 \%$ and maybe as much as $99 \%$ of all natural products are extracted from aerobic source organisms. Distribution of source organisms is shown on the example of publicly available UNPD natural product database (Gu et al., 2013). Sources that are obligately aerobic are colored blue. Fungi, protozoa, and bacteria can be aerobic or anaerobic, depending on species or growth condition (shown in red). Archaea, which are predominantly anaerobic, are shown in black, but only represent $0.07 \%$ of originating species. The fraction of the biosphere on Earth that is anaerobic is unknown, however, the distribution of source organisms above it not typical of the biosphere, in which between $30 \%$ and $50 \%$ of the biomass is known to be bacterial (Whitman et al., 1998). A substantial fraction, possibly $30 \%$, of the total biomass on Earth is represented by the ocean floor sedimentary bacteria, almost all of which are anaerobic (Kallmeyer et al., 2012). If biosynthesis of trivalent phosphorus-containing natural chemicals is strictly dependent on an anoxic environment, it is likely that more of such molecules are going to be discovered in anaerobic source organisms. on aerobic organisms such as insects, plants, and mammals, and usually on model laboratory organisms grown under (aerobic) laboratory or glasshouse conditions (see, e.g., Grivet et al., 2003; Bundy et al., 2009).

The examples of phosphine (Section 2.1) and phospholane (Section 2.2) show that terrestrial life indeed can and does make trivalent phosphorus compounds, and suggest that it only does so in highly anoxic environments. This refutes the argument that life cannot exploit trivalent phosphorus chemistry. We suggest that a more systematic search of completely anoxic environments and the organisms that grow in such environments will find, as well as phosphineproducing organisms, organisms that make other more complex trivalent phosphorus compounds.

It is clear that the discovery of phospholane sets an interesting precedent for a possibility of a much wider utilization of trivalent phosphorus in biochemistry.

\section{Thermodynamics of Synthesis of Trivalent Phosphorus Compounds}

The second of the proposed arguments explaining why terrestrial life does not make trivalent phosphorus compounds, and specifically why life does not directly make phosphine, stems from the thermodynamics of the synthesis of reduced phosphorus compounds. It is argued that trivalent phosphorus compounds must be synthesized by reduction of phosphate, and the enormous energy demand of phosphate reduction makes the synthesis of trivalent phosphorus, and specifically of phosphine, implausible. We argue that the potential thermodynamic limitations of the synthesis of these compounds do not justify the scarcity of trivalent phosphorus chemistry in life. We address our reasoning with two arguments:

First, the energy of synthesis of phosphine is high. Making phosphine from hydrogen and phosphate at neutral $\mathrm{pH}$ at Earth surface temperatures is endergonic. However, making phosphine from phosphite, or from phosphate and $\mathrm{NADH}$, is energy releasing. The thermodynamics and environmental ecology of phosphine formation have been discussed extensively elsewhere (Pasek et al., 2014; Bains et al., 2019) and only summarized here.

There are two pathways that an organism could in principle use to make phosphine; the complete reduction of phosphate and the disproportionation of phosphite. The complete reduction of phosphate to phosphine by NADH can yield energy in warm, highly acid environments $(\mathrm{pH}<2$, temperature $\geq 20^{\circ} \mathrm{C}$ ) or hot, moderately acid environments ( $\mathrm{pH}$ $<5$, temperature $\geq 60^{\circ} \mathrm{C}$ ) (Bains et al., 2019). The production of phosphine by disproportionation of phosphite is energy yielding in a wider set of warm, acidic or cooler, highly acidic environments. Such environments are less extreme and hence more common than those favoring complete reduction of phosphate to phosphine. However, the scenario of production of phosphine from disproportionation of phosphite leaves the open question of the source of phosphite. Bains et al. (2019) note that reduction of phosphate to phosphite using NADH is itself energy yielding in a wide range of cool, neutral, or warm, mildly acid environments. This raises the possibility that a structured ecosystem, with cool, acid, anoxic bottom waters supporting the production of phosphite and warmer surface water supporting its disproportionation, could 
Table 2. Alkyl Phosphines Do Not Require More Energy to Synthesize Than Other Common Volatile Biosignature Gases

\begin{tabular}{|c|c|c|c|c|}
\hline $\begin{array}{l}\text { Examples of potential } \\
\text { volatile secondary } \\
\text { metabolites }\end{array}$ & $\begin{array}{c}\text { Enthalpy of formation } \\
\Delta G_{f}^{\mathrm{o}}\left(\begin{array}{l}(\mathrm{kJ} / \mathrm{mol}) \\
\end{array}\right.\end{array}$ & $\begin{array}{l}\text { Environmental } \\
\text { sources } \\
\text { of elements }\end{array}$ & $\begin{array}{l}\Delta G \text { for synthesis } \\
\text { from environmental } \\
\text { elements }(\mathrm{kJ} / \mathrm{mol})\end{array}$ & Ref. \\
\hline Phosphine & 7.2 & $\mathrm{HPO}_{4}{ }^{2-}, \mathrm{H}_{2}$ & 307 & Sousa-Silva et al. (2019) \\
\hline Trimethyl phosphine & -97.9 & $\mathrm{HPO}_{4}{ }^{2-}, \mathrm{CO}_{2}, \mathrm{H}_{2}$ & 648 & \\
\hline Isoprene & -478.8 & $\mathrm{CO}_{2}, \mathrm{H}_{2}$ & 822 & $\begin{array}{l}\text { Arneth } \text { et al. (2008), } \\
\quad \text { Seager } \text { et al. (2012) }\end{array}$ \\
\hline Dimethyl sulfide & -34.1 & $\mathrm{CO}_{2}, \mathrm{SO}_{4}{ }^{2-}, \mathrm{H}_{2}$ & 693 & Domagal-Goldman et al. (2011) \\
\hline Methyl chloride & -82.9 & $\mathrm{CO}_{2}, \mathrm{Cl}^{-}, \mathrm{H}_{2}$ & -71 & Segura et al. (2005) \\
\hline
\end{tabular}

Two illustrative low-molecular-weight phosphine compounds (phosphine and trimethyl phosphine) are not more energy requiring to make from environmental chemicals than other selected volatile secondary metabolites. Column 1: Examples of potential volatile secondary metabolites. Column 2: Standard free energy of formation. Column 3: Likely sources of elements in the compound on the surface of modern Earth. Column 4: Estimate of Gibbs free energy of synthesis of the potential volatile secondary metabolites from Column 1 from the substrate compounds listed in Column 3, assuming plausible environmental concentrations of substrate compounds in water in Column 3 [see Bains et al. (2019) for more details on the calculation method]. In all cases, free energies of formation are calculated for aqueous species, and are obtained from Robertson and Boyer (1956), Hartley et al. (1963), Barner and Scheurman (1978), Amend and Shock (2001), Linstrom and Mallard (2001), and Fu et al. (2013). Column 5 is a reference for this molecule being a significant product of global bioactivity, and for consideration as a biosignature gas if so considered.

host an ecosystem whose net effect is the reduction of phosphate to phosphine. Environments such as warm swamps, paddy fields, and landfill sites could provide such a structured environment. Indeed reports of environmental phosphine detection most commonly come from such environments (Gassmann and Glindemann, 1993; Devai and Delaune, 1995; Eismann et al., 1997; Han et al., 2000, 2011a, 2011b; Roels and Verstraete, 2004; Ding et al., 2005; Feng et al., 2008a, 2008b; Chen et al., 2017b). Thus, life could produce phosphine in an exergonic process, using phosphine production to capture energy, even if life's sole phosphorus source is phosphate, as extensively discussed in Bains et al. (2019).

Second, we note that life does not only make volatile compounds as a side-product of energy capture. Many compounds are made as a result of functions other than energy capture or biomass production (Seager et al., 2012), and terrestrial life makes many compounds that require substantial energy to make from available chemicals, sometimes in large amounts. As an example, isoprene $\left(\mathrm{C}_{5} \mathrm{H}_{8} ; 2\right.$-methyl-1,3butadiene) is made by many evolutionarily diverse organisms, including plants and algae, bacteria, fungi, protists, and animals (Sharkey, 1996; Logan et al., 2000; Fall and Copley, 2001; Bäck et al., 2010). Globally, life produces 400-600 Tg/ year of $\mathrm{C}_{5} \mathrm{H}_{8}$ (Arneth et al., 2008; Guenther et al., 2012; Hess et al., 2013), and it can comprise up to $20 \%$ of the carbon fixed by some plants (Sharkey and Loreto, 1993). The global production rate of $\mathrm{C}_{5} \mathrm{H}_{8}$ is comparable with that of methane (Guenther et al., 2012; Seinfeld and Pandis, 2016). $\mathrm{C}_{5} \mathrm{H}_{8}$ has a standard heat of formation $\left(\Delta \mathrm{H}_{\mathrm{f}}{ }^{\circ}\right)$ of $75.5 \mathrm{~kJ} / \mathrm{mol}$ (Pedley, 2012), compared with phosphine's $\Delta \mathrm{H}_{\mathrm{f}}^{\mathrm{o}} 5.4 \mathrm{~kJ} / \mathrm{mol}$ (Winget and Clark, 2004). $\mathrm{C}_{5} \mathrm{H}_{8}$ is a larger molecule than phosphine, but life still invests $15.5 \mathrm{~kJ} / \mathrm{mol}$ per carbon atom into making $\mathrm{C}_{5} \mathrm{H}_{8}$, versus the $5.4 \mathrm{~kJ} / \mathrm{mol}$ into one atom of phosphorus in phosphine. The free energy of formation of $\mathrm{C}_{5} \mathrm{H}_{8}$ illustrates the substantial energy investment that organisms make in synthesizing $\mathrm{C}_{5} \mathrm{H}_{8}$ for a useful biological function. It is postulated that $\mathrm{C}_{5} \mathrm{H}_{8}$ is produced in plants at a high energetic cost because it is crucial for thermal regulation, protection against oxidative stress, and signaling (Sharkey et al., 2008).
Energy is also needed to synthesize some other major volatile secondary metabolites. The energy needed to synthesize some of them from environmental chemicals is comparable with that needed to make phosphines (Table 2).

Potential functions that could explain the endergonic production of phosphine could include signaling, defense, or metal capture. Such potential useful biological functions of trivalent phosphorus compounds could be the source of sufficient evolutionary pressure for life to explore this chemistry to a larger extent. Phosphine could be used for signaling as it has all the required properties of a "gasotransmitter" (Wang, 2014). It is highly diffusible, moderately lipid soluble (to allow penetration of cell membranes), and has intermediate water solubility between known gasotransmitters nitric oxide and hydrogen sulfide (Fu et al., 2013), with a low background level and a relatively short half-life in the environment. Phosphine could also function as a defense chemical, as are other reactive toxic species that are made by life such as reactive oxygen species (ROS) (Nauseef, 2007), hydrogen cyanide (Castric, 1975; Knowles and Bunch, 1986), halomethanes (Gribble, 2003, 2009), and cyanogen bromide (Vanelslander et al., 2012). Finally, phosphine could participate in metal capture. Metal phosphides are usually very insoluble, which could allow for phosphine to be part of a mechanism to capture extremely low-abundance metals.

We conclude that the thermodynamic arguments against life's production of trivalent phosphorus chemistry are invalid, for two reasons. Life can extract energy from the synthesis of phosphine in specific anaerobic conditions. Synthesis of phosphine in these conditions could therefore be part of organism's basic energy metabolism, as is the synthesis of better-known volatile products such as hydrogen sulfide and methane. In other conditions on modern Earth, the synthesis of phosphine is endergonic. However, this does not preclude the synthesis of phosphine or other trivalent phosphorus compounds. It is established that life can make substantial energy investment into compounds that provide important biological functionality, and so trivalent phosphorus compounds could be made for energy-consuming reasons. 


\section{Stability and Reactivity of Trivalent Phosphorus Compounds}

The third class of objection toward biological production of trivalent phosphorus compounds claims that they are inherently reactive and hence will not be found in stable metabolites. The principal reactivity of trivalent phosphorus compounds is their facile oxidation to pentavalent phosphorus oxides, which is possible due to the free lone electron pair present on the phosphorus atom. The ease of oxidation of trivalent phosphorus compounds is illustrated by the common observation that many substituted phosphines are spontaneously inflammable (Appendix A; Appendix Table A1). We only discuss the oxidative instability of these compounds briefly. All phosphines, even those that are not spontaneously inflammable, can be readily oxidized to phosphine oxides by atmospheric $\mathrm{O}_{2}$, being completely oxidized in hours or days depending on the ligands (Barder and Buchwald, 2007).

It is possible to create trialkylphosphines that are resistant to oxidation by molecular $\mathrm{O}_{2}$ through internal coordination of an aromatic ring with the phosphorus lone electron pair (Barder and Buchwald, 2007). However, this mechanism only applies to some very specific types of trivalent phosphorus compounds in which the free lone electron pair on the phosphorus atom coordinates internally with the $\Pi$ electrons of an aromatic ring in the compound, and so is not easily sterically accessible.

The rapid oxidation of trivalent phosphorus compounds is only possible in the presence of $\mathrm{O}_{2}$. In an anoxic environment, trivalent phosphorus compounds are kinetically stable to oxidation.

We also note that alkyl phosphines are generally stable to hydrolysis. Phosphine itself (Buckler et al., 1962)-and more easily handled soluble solids such as tributyl phosphine (Sweetman and Maclaren, 1966) or tris(2-carboxyethyl) phosphine (Burns et al., 1991) - is widely used in aqueous solution as a specific reductant (Sweetman and Maclaren, 1966). Water-soluble and stable phosphine derivatives have been developed as ligands for metal catalysts - the phosphines themselves are stable in water as well as the metal complexes they form (Katti et al., 1999; Pinault and Bruce, 2003). Thus, the great majority of trivalent phosphorus compounds are hydrolytically stable. ${ }^{2}$

We conclude that the third argument, that is, that phosphine is highly reactive, does not apply to anoxic environments where phosphines are generally kinetically stable to oxidation and hydrolysis.

\section{Toxicity of Phosphines Is Specific to $\mathrm{O}_{2}$-Dependent Metabolism}

The fourth and final reason cited as to why phosphine and by implication other trivalent phosphorus compounds are not made by life is that they are broadly toxic.

Phosphine is highly toxic to aerobically metabolizing organisms (Bond et al., 1967), including many vertebrate

\footnotetext{
${ }^{2}$ Phosphorous acid triesters (trivalent phosphorus compounds with phosphorus in the +3 oxidation state) are one family of trivalent phosphorus compounds that rapidly hydrolyze in water, sometimes explosively.
}

and invertebrate animals. It is acutely toxic to humans ${ }^{3}$ at $50 \mathrm{ppm}$ and dangerous for chronic exposure at $>0.1 \mathrm{ppm}$ (reviewed in Bingham, 2001; Perkins et al., 2015). Direct poisoning by phosphine is relatively rare, mainly because phosphine itself is a rare gas on Earth. Most phosphine poisoning cases arise as a consequence of ingesting phosphides, which are used as pesticides. Phosphides very rapidly release phosphine on hydrolysis, primarily in the stomach through action of stomach acid (reviewed in Bumbrah et al., 2012; Sciuto et al., 2016; Mew et al., 2017). We note, however, that phosphide ingestion cannot be the source of the phosphine found in the flatus of healthy humans or other animals (Section 2). Phosphide ingestion is rare, it generates phosphine in the upper gastrointestinal tract, and has a rapid onset of toxicity, none of which is consistent with finding phosphine in animals' bowels.

There are several potential mechanisms for the broad toxic properties of phosphines, all of which are strictly dependent on an aerobic metabolism (reviewed in Valmas et al., 2008).

It is believed that phosphine's principal direct toxic effect is through inhibition of mitochondrial cytochrome $\mathrm{C}$ oxidase (Complex IV), and hence, the blockade of oxidative phosphorylation and collapse of the mitochondrial membrane potential (Chefurka et al., 1976; Bolter and Chefurka, 1990b; Valmas et al., 2008). This inhibition and subsequent blockage cause widespread metabolic crisis and generation of reactive oxygen species (ROS), both of which cause lethal damage (Bolter and Chefurka, 1990b; Zuryn et al., 2008; Dua et al., 2010). Phosphine also inhibits catalase (Price and Dance, 1983; Hobbs and Bond, 1989; Hsu et al., 2002) and some peroxidase enzymes (Hsu et al., 2002), enzymes that defend against ROS (Kashi and Chefurka, 1976; Hobbs and Bond, 1989; Chaudhry and Price, 1990). Inhibition of ROS defense enzymes will exacerbate the toxic effect of phosphine. These effects are acting on biochemistry common to aerobic energy production in mitochondria and bacteria, and so, it is plausible to suggest that any antifungal effects of phosphine are also due to $\mathrm{O}_{2}$-dependent mechanisms (Leitao et al., 1987, 1990).

It is also possible that phosphine reacts with hydrogen peroxide $\left(\mathrm{H}_{2} \mathrm{O}_{2}\right)$ in the presence of other species to form ROS. For example, lipids are oxidized efficiently in the presence of phosphine and $\mathrm{H}_{2} \mathrm{O}_{2}$, but not in the presence of either on their own (Quistad et al., 2000). Pure phosphine does not react with pure $\mathrm{H}_{2} \mathrm{O}_{2}$ (Fluck, 1973), but in the presence of iron, phosphine does react with ROS such as $\mathrm{H}_{2} \mathrm{O}_{2}$, and iron overload increases the toxicity of phosphine (Cha'on et al., 2007). It is likely that phosphine accelerates Fenton reactions between $\mathrm{Fe}$ and $\mathrm{H}_{2} \mathrm{O}_{2}$. The

\footnotetext{
${ }^{3}$ A little-known fact, supporting the notion of specific toxicity of $\mathrm{PH}_{3}$ toward aerobic life presented in this section, is that phosphine was used as chemical warfare agent (CWA) during the First World War (WWI: 1914-1918) (Ireland, 1926; McElroy and Day, 2016; Warthin and Weller, 1919). $\mathrm{PH}_{3}$, although not used as frequently as chlorine, carbonyl chloride (phosgene) or dichloroethyl sulfide (mustard gas), is an example of more than 40 different chemical substances used as CWAs during the First World War (not counting various mixtures of CWAs that were sometimes classified as separate agents of chemical warfare) (Ireland, 1926; Warthin and Weller, 1919).
} 
Fenton reaction is the cyclic reaction of iron and $\mathrm{H}_{2} \mathrm{O}_{2}$, which is summarized thus:

$$
\begin{aligned}
& \mathrm{Fe}^{2+}+\mathrm{H}_{2} \mathrm{O}_{2} \rightarrow \mathrm{Fe}^{3+}+\mathrm{HO} \bullet+\mathrm{OH}^{-} \\
& \mathrm{Fe}^{3+}+\mathrm{H}_{2} \mathrm{O}_{2} \rightarrow \mathrm{Fe}^{2+}+\mathrm{HOO} \bullet+\mathrm{H}^{+}
\end{aligned}
$$

Reaction (2) is much slower than reaction (1), especially at neutral pH (reviewed in Pignatello et al., 2006). However, phosphine efficiently reduces $\mathrm{Fe}^{3+}$ to $\mathrm{Fe}^{2+}$, independently of whether $\mathrm{Fe}^{3+}$ is present as free metal ions or bound, for example, in cytochromes (Kashi and Chefurka, 1976; Hobbs and Bond, 1989; Chaudhry and Price, 1990), and so would accelerate reaction (2), thus accelerating the overall rate of Fenton-type damage chemistry.

Thus, as a toxin, phosphine has four likely interrelated effects:

1. Blockade of electron transport in respiration, thereby causing mitochondrial or bacterial membrane potential collapse and failure of energy generation.

2. Enhancing the production of $\mathrm{H}_{2} \mathrm{O}_{2}$ and ROS by blocking cytochrome $\mathrm{C}$ oxidase.

3. Enhancing the generation of ROS from $\mathrm{H}_{2} \mathrm{O}_{2}$ by catalyzing Fenton chemistry.

4. Blocking the cell's subsequent defence against ROS.

The result of exposure to phosphines is both reduction in energy supply and increase in damage to cells that are dependent on oxidative metabolism. In fact, all of the mechanisms above are solely the result of the interaction of phosphine with oxidative metabolism. No part of this proposed mechanism of toxicity of phosphines will affect completely anoxic organisms. This observation is supported by several studies that suggest that organisms lessdependent on aerobic metabolism are largely immune to the toxic effect of phosphine (Bond and Monro, 1967; Bond et al., 1967; Nath et al., 2011; Sciuto et al., 2016; Shakoori et al., 2016).

We note that the toxicity mechanisms presented above are known through terrestrial biochemistry, but may not be limited to it. Phosphine's effects on both cytochrome C oxidase and ROS defence enzymes are probably due to direct binding of phosphine to the heme iron atom. The direct binding of phosphine to the heme iron atom is a chemical effect, independent of the enzymatic context of the iron (with the access caveat discussed in the paragraph below and Fig. 2). As iron is the most abundant redox-active metal in the Earth's crust, it is plausible that life on other planets with $\mathrm{O}_{2}$-rich environments could use iron in $\mathrm{O}_{2}$-dependent chemistry as well, and hence be similarly vulnerable to that chemistry being inhibited by phosphine. Fenton reactions shown above will be universal wherever iron and $\mathrm{O}_{2}$ species are found (see Fig. 2 for a summary of the mechanisms of toxicity of trivalent phosphorus chemistry toward $\mathrm{O}_{2}$ dependent organisms).

There is much less research published on the mechanisms of toxicity of organophosphines (molecules in which one or more of the hydrogen atoms in phosphine are replaced by an organic group). Methylphosphine is roughly as toxic as phosphine to insects (Chaudhry et al., 2000). The only systematic study of the toxicity of other substituted phos- phines is by Waritz and Brown (1975), who showed that higher molecular weight alkyl- and aryl-phosphines show lower toxicity to aerobic organisms, and that the time and tissue distribution of toxic effects is different for phosphine, phenyl phosphine, and triphenyl phosphine. A passing comment in Waritz and Brown (1975) suggests that trioctyl phosphine also adheres to this pattern. Such an observation is consistent with the notion that large side chain groups bonded to the phosphorus atom are blocking the access of the free lone electron pair of the phosphorus atom to the heme iron in cytochrome oxidase, preventing efficient $\mathrm{Fe}$ complexation and in turn lowering the detrimental toxic effect of higher molecular weight phosphines (Fig. 2). Alkylphosphines in which the phosphorus lone electron pair is stably coordinated to another group are not toxic, supporting the idea that phosphine's toxicity is due to its coordination to metal (Hood, 1972; Best and Sadler, 1996).

A series of studies on resistance to phosphine poisoning in invertebrates also supports the mechanisms of the selective toxicity of phosphines toward $\mathrm{O}_{2}$-dependent organisms proposed above. Aerobic organisms can render phosphine relatively nontoxic through either of the two possible mechanisms. The first is the complete removal of $\mathrm{O}_{2}$ and shutdown of aerobic metabolism. This approach is not possible for vertebrates, but is possible in some insects; for this reason, phosphine can be ineffective against some dormant forms of insects (reviewed in Nath et al., 2011; Shakoori et al., 2016). The second mechanism (also observed in insects) involves the increase in the expression levels of ROS-defence enzymes such as superoxide dismutase, catalase, and peroxidase in response to phosphine (Bolter and Chefurka, 1990a), to counteract the direct inhibition of those enzymes (e.g., catalase) by phosphine (Fig. 2).

In summary, phosphine itself is relatively nontoxic in anaerobic environments, and other trivalent phosphorus compounds are likely to have an even less toxic effect in anoxic conditions. In this regard, in strictly anoxic environments, trivalent phosphorus compounds are no more toxic than hydrogen sulfides, thiols, or thioethers, allowing for potentially much more widespread utilization of trivalent phosphorus chemistry by anaerobic life with $\mathrm{O}_{2}$-independent metabolism. Therefore, while trivalent phosphorus compounds are avoided due to toxicity by aerobic life, anaerobic life could still use and produce phosphine and other trivalent phosphorus compounds.

\section{Discussion}

Understanding why life uses the chemistry that it does is a fundamental question in biology. We argue that, given the enormous diversity of possible chemical space, it is just as important to explain why life does not utilize certain chemical functionalities. There are a wide range of hypotheses published as to why life uses certain specific chemical functionalities [e.g., peptide bond, phosphates (Westheimer, 1987; Pace, 2001; Benner et al., 2004)]. In contrast, apart from a single recently published work presenting the hypothesis for reasons behind scarcity of the N-S bondcontaining compounds in biochemistry (Petkowski et al., 2019a), there are no studies that address the question why life does not use certain specific chemical classes of molecules that are chemically flexible, stable, and have wide 

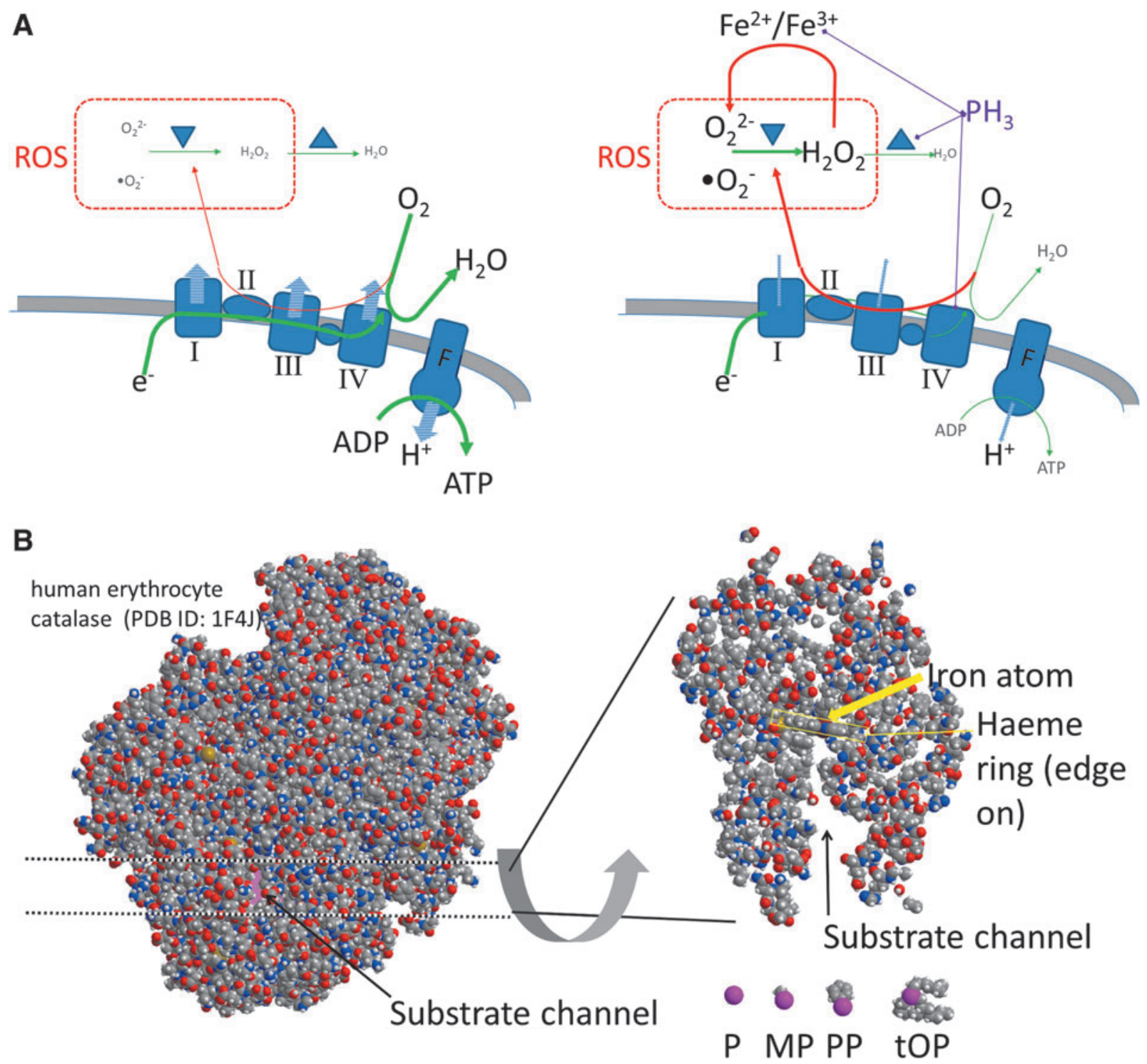

FIG. 2. (A) Proposed mechanisms of phosphine's toxicity toward organisms with $\mathrm{O}_{2}$-dependent metabolism. Left panel: During normal respiration, electrons from metabolism pass down the respiratory electron transport chain (components I through III) to cytochrome $\mathrm{C}$ oxidase (Complex IV). Cytochrome $\mathrm{C}$ oxidase passes the electrons to oxygen, reducing it to water. A low level of leakage of electrons from the electron transport pathway reacts directly with oxygen to generate highly toxic ROS such as superoxide and peroxide. Superoxide dismutase (downward pointing triangle) converts these to the less reactive but still toxic $\mathrm{H}_{2} \mathrm{O}_{2}$. Catalase (upward pointing triangle) converts $\mathrm{H}_{2} \mathrm{O}_{2}$ to water. Components I, III, and IV of the electron transport chain pump protons out of the mitochondrion as electrons pass through them (striped arrows). The FATPase allows these protons to flow back into the mitochondrion, and couples this to the synthesis of ATP. Right panel: Four actions of phosphine. Phosphine blocks cytochrome $\mathrm{C}$ oxidase (Complex IV). Inhibition of cytochrome C oxidase blocks the normal flow of electrons to water, and some electrons flow to ROS generation instead. Inhibition of Complex IV also largely prevents the pumping of protons, so F-ATPase cannot function, and so, ATP is not generated. Phosphine also blocks catalase, so $\mathrm{H}_{2} \mathrm{O}_{2}$ cannot be safely disproportionated to water. Phosphine may also catalyze the $\mathrm{Fenton} \mathrm{Fe}^{2+} / \mathrm{Fe}^{3+}$ chemistry that converts some $\mathrm{H}_{2} \mathrm{O}_{2}$ to the more reactive superoxide and peroxide ions. (B). Large alkylphosphine analogs are less toxic than phosphine itself. Phosphine interacts directly with the heme iron in cytochrome C oxidase (Complex IV) and catalase. In both enzymes, the heme ring is deeply buried in the protein fold. We illustrate this with human erythrocyte catalase (PDB ID: 1F4J; Safo et al., 2001). Left structure-the catalase tetramer viewed down the channel leading to the heme ring in one subunit. The heme ring has been colored purple to make visualization easier. Two dotted lines show where a slice is taken through the structure and rotated in the right panel. The very narrow channel to the heme iron is clear. The structures of P, MP, PP, and tOP are shown below the protein structure slice on the same scale for comparison. All structures are represented in space-filling with CPK atom coloring and standard van der Waals radii. Only P and MP are small enough to efficiently penetrate the access channel and interact directly with the heme iron, while the access of PP and tOP is significantly sterically hindered. This observation is consistent with the previous literature data, suggesting that $\mathrm{P}$ and MP exhibit similar high levels of toxicity, while PP and tOP are much less toxic (Waritz and Brown, 1975). ADP, adenosine diphosphate; ATP, adenosine triphosphate; $\mathrm{H}_{2} \mathrm{O}_{2}$, hydrogen peroxide; MP, methylphosphine; $\mathrm{O}_{2}$, oxygen; P, phosphine; $\mathrm{PH}_{3}$, phosphine gas; PP, phenylphosphine; ROS, reactive oxygen species; tOP, trioctylphosphine. 
chemical and structural functionality. Our work on the scarcity of trivalent phosphorus chemistry in biochemistry presented here is a continuation of a larger effort that aims to identify areas of chemical space that life avoids, and to provide explanations why each case is so. We hope that this effort will provide insight into life's evolution through chemical space and therefore into the origin and early evolution of life.

We have critically reviewed and discussed four arguments for the general scarcity of trivalent phosphorus chemistry in biochemistry. We summarize our observations as follows.

We present evidence that the first argument, that there is no precedent for life's use of trivalent phosphorus, cannot justifiably be used as an explanation for the scarcity of this chemistry in biology (Section 2). Phosphine and phospholane are made by terrestrial life. The great majority of identified natural compounds were isolated from $\mathrm{O}_{2}$-rich environments (Fig. 1), resulting in a strong bias of natural product collections toward compounds isolated from aerobic organisms. We suggest that a more systematic examination of completely anoxic environments and the organisms that grow in them will find phosphine as well as other, more complex, trivalent phosphorus compounds.

The second argument suggests that there are severe energetic limitations to production of reduced phosphorus species, especially phosphines. In contradiction to this, we have argued before that phosphine production can be exergonic in acidic reducing environments (Bains et al., 2019). Even outside such environments, the thermodynamics of formation of trivalent phosphorus compounds is no less favorable than the energy of formation of other volatile compounds made in sufficient amounts by life to be significant trace gases in Earth's atmosphere (Section 3).

The third argument suggests that trivalent phosphorus compounds are rapidly oxidized to their phosphorus oxides by molecular $\mathrm{O}_{2}$, which makes their synthesis and usefulness in an $\mathrm{O}_{2}$-rich environment unlikely (Section 4). Obviously, this does not apply to anoxic environments where phosphines are generally kinetically stable to oxidation and hydrolysis. 4

Similarly, the fourth argument justifying the scarcity of trivalent phosphorus chemistry in life (the broad toxic effects of phosphine chemistry) does not apply to anoxic environments. We have provided detailed explanations as to why the toxicity of phosphines is strictly $\mathrm{O}_{2}$-dependent (Section 5), and affects only organisms utilizing oxidative metabolism.

In summary, all of the reasons that trivalent phosphorus compounds are not expected to be part of biochemistry apply only to $\mathrm{O}_{2}$-rich environments. None applies to strictly anoxic reducing environments. We speculate therefore that the almost complete absence of trivalent phosphorus compounds from modern terrestrial surface life is because of Earth's $\mathrm{O}_{2}$-rich atmosphere. Life has an apparent "choice": the ecosphere can exploit trivalent phosphorus chemistry or

\footnotetext{
${ }^{4}$ Phosphines are not thermodynamically stable to hydrolysis under anoxic conditions, but then neither are proteins, nucleic acids, carbohydrates, adenosine triphosphate, NADH, and indeed most of metabolism.
}

have $\mathrm{O}_{2}$-dependent metabolism, but not both. Life in environments other than the modern $\mathrm{O}_{2}$-rich terrestrial surface could use trivalent phosphorus compounds more extensively. We believe that our work has implications for life's evolution through chemical space and therefore into the origin and early evolution of both terrestrial and nonterrestrial life. We expand on life's evolution through chemical space implications below.

\subsection{Trivalent phosphorus compounds and the origin of life}

Several groups have speculated in the past that intermediate oxidation states of phosphorus might have been important in the origin of life on Earth (Schwartz, 2006; Pasek, 2008; Bryant et al., 2010; Pasek and Kee, 2011). It has also been suggested that a significant fraction of phosphorus in the Archean ocean was present as phosphite, not phosphate (Pasek, 2008; Pasek et al., 2013; Herschy et al., 2018). Our discussion here supports that broad theme, in suggesting that in the absence of molecular $\mathrm{O}_{2}$, trivalent phosphorus compounds could have played significant roles in origin of life scenarios, as well as the reduced pentavalent phosphites and phosphinates, as suggested by Bryant et al. (2010) and Pasek and Kee (2011).

It was also speculated that life originating in environments where phosphates and other phosphorus oxides are not readily available may incorporate phosphines in its biochemistry (Pasek et al., 2011). Examples of such "phosphine friendly" environments include hydrocarbon seas and lakes on Saturn's moon Titan. It was suggested that, in contrary to Earth, Titan's phosphorus chemistry is dominated by phosphines (Pasek et al., 2011). Photochemical reactions of phosphine likely could lead to the formation of complex organophosphines, contributing to the hydrocarbon cycle and in haze chemistry in Titan's atmosphere (Guillemin et al., 1995). Thus, if putative life on Titan uses phosphorus, it would likely have to use phosphines in its biochemistry.

We urge chemists working on the origin of life to consider mechanisms under which trivalent phosphorus compounds could play a more prominent role in prebiotic chemistry. We recognize that this is not a trivial exercise. Many phosphine derivatives, apart from their common broad toxicity, can have spectacularly unpleasant smells, a characteristic that is often insufficiently reported in chemical literature (Fluck, 1973; OrgPrepDaily, 2008). However, the concepts presented here suggest that it would be worthwhile.

\subsection{Trivalent phosphorus compounds as possible markers of the Shadow Biosphere on Earth}

The Shadow Biosphere is a conceptual domain of life that is chemically (and hence genetically) distinct from the dominant life on Earth's surface (Cleland and Copley, 2006; Davies et al., 2009). A Shadow Biosphere must occupy an ecological niche that is substantially distinct from Earth's surface, as the idea that two distinct forms of life with two distinct biochemistries have survived in the same habitat for more than 3.5 billion years is implausible. Thus, the Shadow Biosphere is most likely to occupy a niche that is physically or chemically substantially different from that occupied by common surface life. An issue for research into the Shadow 
Biosphere is how it can be detected. If Shadow Biosphere life uses DNA as a genetic material, then metagenomic surveys will detect it. However, if it does not (if, e.g., it uses alternative bases, RNA, modified sugars, or other forms of nucleic acid that are poorly processed by routine metagenomic methods), then it will have to be detected by its unique chemical signature.

Searching for a Shadow Biosphere therefore requires a method of detecting chemical biosignatures that (a) are unlikely to be geological, (b) are very unlikely to be the product of known surface life, and (c) could reasonably be the product of metabolism. We suggest that trivalent phosphorus compounds could be a valuable marker for a Shadow Biosphere. Such compounds are extremely unlikely to be made geochemically (reviewed in Sousa-Silva et al., 2019), so the chances of a trivalent phosphorus "false positive" are small. Trivalent phosphorus appears to be used in fairly limited chemical contexts in the major surface life-forms on Earth, and so finding, for example, compounds such as phosphine analogues of amino acids would be a signature of biochemistry, at least very highly diverged from the surface consensus. Use of ${ }^{31} \mathrm{P}$ NMR could be a low-cost and simple screening tool for the presence of trivalent phosphorus compounds in samples that might contain members of the Shadow Biosphere.

\subsection{Trivalent phosphorus compounds as potential biosignature gases on anoxic exoplanets}

Currently, a major focus in exoplanet astronomy is the near-future detection of the presence of life on exoplanets through detection of gases in exoplanet atmospheres that may be attributed to biological activity (Seager and Bains, 2015; Seager et al., 2016; Catling et al., 2018; Schwieterman et al., 2018). A wide range of gases have been suggested, and a smaller number studied, as candidate biosignatures (Seager et al., 2012). Recently, phosphine has been added to this list as a candidate biosignature gas; Sousa-Silva et al. (2019) provide a critical analysis of phosphine as a biosignature in exoplanets with anoxic atmospheres. As a biosignature, phosphine has three advantages. First, it has spectral features that are easily distinguishable from other dominant atmospheric gases. Second, phosphine is unlikely to condense into cloud aerosols (as ammonia, hydrogen sulfide, and methanethiol would do), although it may form organophosphine hazes in hydrocarbon-rich atmospheres. Third, there are no known geochemical false-positive sources for phosphine, providing the planet has a solid (rocky) surface with a temperature and pressure suitable for liquid water [phosphine is found in gas giant atmospheres, as it is formed deep in the atmosphere at temperatures in excess of $800 \mathrm{~K}$ (Visscher et al., 2006)]. Photochemical modeling shows that, for suitable planets around quiet $\mathrm{M}$ dwarf stars, fluxes as low as $10^{-10}$ moles per meter squared per second could be detected (Sousa-Silva et al., 2019). By contrast, methyl chloride, a very well-studied trace biosignature gas (Segura et al., 2005), has a total global flux from Earth of between $6 \times 10^{-12}$ and $10^{-10} \mathrm{M} / \mathrm{m}^{2} / \mathrm{s}$ (Seager et al., 2013).

However, the value of phosphine as a biosignature is only relevant to detecting life on another world if that life produces phosphine. Our arguments here and the thermodynamic calculations presented in detail elsewhere (Bains et al., 2019) suggest that life elsewhere could indeed produce phosphine or other trivalent phosphorus compounds in significant amounts if the exoplanet environments were anoxic and reducing. On Earth, phosphine detected in biogas from sewage plants can reach very high levels, for example, $10^{-6} \mathrm{M} / \mathrm{m}^{2} / \mathrm{s}$ (Devai et al., 1988). It is therefore plausible that a complex, global, and anaerobic biosphere on exoplanets, similar to that found in sludges on Earth, could result in comparable phosphine production levels (SousaSilva et al., 2019).

\subsection{Anaerobic natural product chemistry}

The large majority of compounds recorded in databases of natural products are derived from aerobic organisms (Fig. 1) or organisms grown in aerobic conditions. Our hypothesis postulates that the reason for extreme scarcity of trivalent phosphorus compounds in biochemistry is caused by the $\mathrm{O}_{2}-$ rich environment of modern Earth. As discussed in Sections 4 and 5, in anoxic environments, trivalent phosphorus compounds would be much less reactive and organisms whose metabolism is not dependent on $\mathrm{O}_{2}$ would be largely immune to the toxic effects of such compounds. If our hypothesis is correct, we predict that organisms living in strictly anoxic environments should be able to explore trivalent phosphorus chemistry to a much larger extent than $\mathrm{O}_{2}$-dependent life. Directed searches in anaerobic organisms for secondary metabolites have been productive in the past (e.g., Michael et al., 1993; Banala and Süssmuth, 2010; Thorger et al., 2010; Behnken and Hertweck, 2012), yielding a variety of sulfur-containing compounds. We suggest that focused directed searching for novel phosphorus-containing compounds in anaerobic environments could also be productive. ${ }^{5}$ The discovery of phospholane in mammalian feces (Davies, 2008) points to one environment that could be searched. Others include anoxic hydrothermal systems, waterlogged soils, anoxic lake or swamp beds, or landfill sites.

Conventional search methods for new compounds in such environments are usually based on extraction of a sample followed by gas chromatography/mass spectrometry analysis.

\footnotetext{
${ }^{5}$ A place to search could be sites of occurrence of the "Will-othe-wisp," very faint, cold, blue-tinted light occasionally seen hovering or moving over marshy ground (Edwards, 2014; Żychowski, 2014). The idea that "Will-o-the-wisp" was methane burning, ignited by the spontaneous ignition of phosphine in air, dates back to the 1940s (Harvey, 1940) or before. However, it has been known since the 1890s that pure phosphine is not spontaneously inflammable (Retgers, 1894); the spontaneous inflammability of phosphine generated by hydrolysis of phosphides is the result of the spontaneous inflammability of diphosphine contaminant. It has been argued that if "Will-o-the-wisp" is methane ignited by a phosphorus volatile, that volatile must be diphosphine made by acid attack on phosphides, and in consequence "Will-o-the-wisp" is not evidence for biological production of phosphine. However, this argument is not conclusive if microbial life makes volatile trivalent phosphorus compounds other than phosphine. While phosphine itself is not spontaneously inflammable, many alkyl phosphines are, Appendix A (Appendix Table A1). If life made alkyl phosphines [by analogy with its synthesis of thiols and thioethers as well as hydrogen sulfide (reviewed by Schulz and Dickschat, 2007)], then those could ignite the methane to create "Will-o-the-wisp." Phosphine oxidation can also lead to green and blue chemiluminescence (Hamilton and Murrels, 1986), which would also explain the "Willo-the-wisp" phenomenon. Testing this idea by field sampling would be difficult but tractable in principle.
} 
Isolating trivalent phosphorus compounds could be challenging, because such compounds are inherently liable to oxidation, resulting in oxidized pentavalent products that could be falsely identified as original natural products. However, if it is realized that $\mathrm{O}_{2}$-sensitive metabolites could be made in anoxic environments, suitable extraction and analysis strategies can readily be used. Mass spectrometric analysis of phosphorus compounds or samples rich in phosphates can also be difficult, requiring development of additional purification steps. However, the NMR techniques mentioned above in Section 2.2 might be an attractive alternative for detecting phosphine and alkylphosphines in environmental samples. If trivalent phosphine was present as $>1 \%$ of the total phosphorus present, it could be directly and unambiguously detected by NMR.

If natural production of trivalent phosphorus-containing natural chemicals is strictly dependent on the anoxic environment, it is likely that more of such molecules are going to be discovered in the future once natural products' chemistry of anaerobic environments gets more attention and momentum.

\section{Conclusions}

We have presented evidence that trivalent phosphorus compounds, such as phosphines, could be components of, and biosignature compounds for, life in anoxic environments. The four classes of arguments as to why life on Earth does not use phosphines derive from precedent, thermodynamics, stability, and toxicity. We show that in fact two of these are misapprehensions, and the other two do not apply to life in the absence of molecular $\mathrm{O}_{2}$. Thus, we conclude that trivalent phosphorus compounds, and specifically phosphines, could both be valuable biosignatures in the search for life on anoxic exoplanets or the search for a Shadow Biosphere on Earth, and interesting subjects for research into the potential chemistry of the very earliest life. Regarding the latter, we recognize that phosphine chemistry is not easy to explore. $\mathrm{PH}_{3}$ itself is noxious and poisonous, and many phosphine derivatives are also toxic and have strong and extremely unpleasant smells. Nevertheless, we encourage efforts to further explore the biochemistry of this understudied class of chemicals.

\section{Acknowledgments}

We thank MIT, the MIT Amar G. Bose Research Grant, the Change Happens Foundation, and the Heising-Simons Foundation for support. We also thank Michael J. Evans (Georgia Tech) for suggesting the Sigma-Aldrich safety data sheets. We are grateful to the reviewers of this article for helpful suggestions, and particularly to one reviewer for suggesting the usefulness of NMR as an analytical tool.

\section{Author Disclosure Statement}

The authors declare that they have no conflicts of financial or other interests relating to this work.

\section{References}

Allen, D.W. (2012) Phosphines and related P-C-bonded compounds. In Organophosphorus Chemistry, Vol. 43, edited by
D.W. Allen, J.C. Tebby, and D. Loakess, Royal Society of Chemistry, London, England, pp 1-51.

Amend, J.P. and Shock, E.L. (2001) Energetics of overall metabolic reactions of thermophilic and hyperthermophilic Archaea and Bacteria. FEMS Microbiol Rev 25:175-243.

Arneth, A., Monson, R.K., Schurgers, G., Niinemets, U., and Palmer, P.I. (2008) Why are estimates of global terrestrial isoprene emissions so similar (and why is this not so for monoterpenes)? Atmos Chem Phys 8:4605-4620.

Bäck, J., Aaltonen, H., Hellén, H., Kajos, M.K., Patokoski, J., Taipale, R., Pumpanen, J., and Heinonsalo, J. (2010) Variable emissions of microbial volatile organic compounds (MVOCs) from root-associated fungi isolated from Scots pine. Atmos Environ 44:3651-3659.

Bains, W., Petkowski, J.J., Sousa-Silva, C., and Seager, S. (2019) New environmental model for thermodynamic ecology of biological phosphine production. Sci Total Environ 658:521-536.

Banala, S. and Süssmuth, R.D. (2010) Thioamides in nature: in search of secondary metabolites in anaerobic microorganisms. Chembiochem 11:1335-1337.

Barder, T.E. and Buchwald, S.L. (2007) Rationale behind the resistance of dialkylbiaryl phosphines toward oxidation by molecular oxygen. J Am Chem Soc 129:5096-5101.

Barner, H.E. and Scheurman, R.V. (1978) Handbook of Thermochemical Data for Compounds and Aqueous Species. Wiley Interscience, New York, NY.

Behnken, S. and Hertweck, C. (2012) Anaerobic bacteria as producers of antibiotics. Appl Microbiol Biotechnol 96:61-67.

Benner, S.A., Ricardo, A., and Carrigan, M.A. (2004) Is there a common chemical model for life in the universe? Curr Opin Chem Biol 8:672-689.

Berg, J.M., Tymoczko, J.L., and Stryer, L. (2002) Biochemistry. Freeman, New York.

Best, S.L. and Sadler, P.J. (1996) Gold drugs: mechanism of action and toxicity. Gold Bull 29:87-93.

Bingham, E. (2001) Phosphorus, selenium, tellurium and sulfur. In Patty's Toxicology, 5th ed., Vol. 3, edited by E. Bingham, B. Cohrssen, and C.H. Powells, John Wiley, New York, NY, pp 459-517.

Bolter, C.J. and Chefurka, W. (1990a) The effect of phosphine treatment on superoxide dismutase, catalase, and peroxidase in the granary weevil, Sitophilus granarius. Pestic Biochem Physiol 36:52-60.

Bolter, C.J. and Chefurka, W. (1990b) Extramitochondrial release of hydrogen peroxide from insect and mouse liver mitochondria using the respiratory inhibitors phosphine, myxothiazol, and antimycin and spectral analysis of inhibited cytochromes. Arch Biochem Biophys 278:65-72.

Bond, E.J. and Monro, H.A.U. (1967) The role of oxygen in the toxicity of fumigants to insects. J Stored Prod Res 3:295-310.

Bond, E.J., Monro, H.A.U., and Buckland, C.T. (1967) The influence of oxygen on the toxicity of fumigants to Sitophilus granarius (L). J Stored Prod Res 3:289-294.

Brune, A., Emerson, D., and Breznak, J.A. (1995) The termite gut microflora as an oxygen sink: microelectrode determination of oxygen and $\mathrm{pH}$ gradients in guts of lower and higher termites. Appl Environ Microbiol 61:2681-2687.

Brunner, H. and Sievi, R. (1987) Asymmetric catalyses: XXXIII. New optically active phospholanes derived from tartaric acid. J Organomet Chem 328:71-80.

Bryant, D.E., Marriott, K.E.R., Macgregor, S.A., Kilner, C., Pasek, M.A., and Kee, T.P. (2010) On the prebiotic potential of reduced oxidation state phosphorus: the H-phosphinatepyruvate system. Chem Commun 46:3726-3728. 
Buckler, S.A., Doll, L., Lind, F.K., and Epstein, M. (1962) Phosphine as a reducing agent. J Org Chem 27:794-798.

Budavari, S., O’Neil, M.J., Smith, A., Heckelman, P.E., and Kinneary, J.F. (1996) The Merck Index. Merck Research Laboratories Division of Merck \& Co. Inc., Whitehouse Station, NJ, USA. pp 137-138.

Bumbrah, G.S., Krishan, K., Kanchan, T., Sharma, M., and Sodhi, G.S. (2012) Phosphide poisoning: a review of literature. Forensic Sci Int 214:1-6.

Bundy, J.G., Davey, M.P., and Viant, M.R. (2009) Environmental metabolomics: a critical review and future perspectives. Metabolomics 5:3.

Buono, G., Toselli, N., and Martin, D. (2008) Phosphorus Ligands in Asymmetric Catalysis. A. Börner, Wiley-VCH, Weinheim, p 529.

Burns, J.A., Butler, J.C., Moran, J., and Whitesides, G.M. (1991) Selective reduction of disulfides by tris(2-carboxyethyl) phosphine. J Org Chem 56:2648-2650.

Cahill, M.M. (1990) Bacterial flora of fishes: a review. Microb Ecol 19:21-41.

Cao, H., Liu, J.A., Zhuang, Y., and Dietmar, G. (2000) Emission sources of atmospheric phosphine and simulation of phosphine formation. Sci China Series B Chem 43:162-168.

Castric, P.A. (1975) Hydrogen cyanide, a secondary metabolite of Pseudomonas aeruginosa. Can J Microbiol 21:613-618.

Catling, D.C., Krissansen-Totton, J., Kiang, N.Y., Crisp, D., Robinson, T.D., DasSarma, S., Rushby, A.J., Del Genio, A., Bains, W., and Domagal-Goldman, S. (2018) Exoplanet biosignatures: a framework for their assessment. Astrobiology 18:709-738.

Cha'on U., Valmas, N., Collins, P.J., Reilly, P.E.B., Hammock, B.D., and Ebert, P.R. (2007) Disruption of iron homeostasis increases phosphine toxicity in Caenorhabditis elegans. Toxicol Sci 96:194-201.

Chaudhry, M.Q. and Price, N.R. (1990) A spectral study of the biochemical reactions of phosphine with various haemproteins. Pestic Biochem Physiol 36:14-21.

Chaudhry, M.O., Macnicoll, A.D., and Price, N.R. (2000) Alkylphosphines as Pesticidal Agents. USPTOs, Alexandria, VA.

Chefurka, W., Kashi, K.P., and Bond, E.J. (1976) The effect of phosphine on electron transport in mitochondria. Pestic Biochem Physiol 6:65-84.

Chen, C., Wang, L., Chen, S., Wu, X., Gu, M., Chen, X., Jiang, S., Wang, Y., Deng, Z., Dedon, P.C., and Chen, S. (2017a) Convergence of DNA methylation and phosphorothioation epigenetics in bacterial genomes. Proc Natl Acad Sci U S A 114:4501-4506.

Chen, W., Niu, X., An, S., Sheng, H., Tang, Z., Yang, Z., and $\mathrm{Gu}, \mathrm{X}$. (2017b) Emission and distribution of phosphine in paddy fields and its relationship with greenhouse gases. Sci Total Environ 599-600:952-959.

Chughtai, M. and Pridham, J.B. (1998) Determination of phosphine by packed column gas chromatography with alkali flame ionisation detection. Anal Comm 35:109-111.

Clarke, M.L. and Williams, J.M.J. (2004) The synthesis and applications of phosphines. In Organophosphorus Reagents: A Practical Approach in Chemistry, edited by P. Murphys, Oxford University Press, Oxford, UK.

Cleland, C.E. and Copley, S.D. (2006) The possibility of alternative microbial life on Earth. Int J Astrobiol 4:165-173.

Davies, M.J. (2008) Chemical Communication in the European Otter, Lutra lutra. PhD thesis, University of Hull, Hull, England.
Davies, P.C.W., Benner, S.A., Cleland, C.E., Lineweaver, C.H., McKay, C.P., and Wolfe-Simon, F. (2009) Signatures of a shadow biosphere. Astrobiology 9:241-249.

Devai, I. and Delaune, R.D. (1995) Evidence for phosphine production and emission from Louisiana and Florida marsh soils. Org Geochem 23:277-279.

Devai, I., Felfoldy, L., Wittner, I., and Plosz, S. (1988) Detection of phosphine: new aspects of the phosphorus cycle in the hydrosphere. Nature 333:343-345.

Ding, L., Liang, H., Zhu, Y., Mo, W., Wang, Q., Ren, H., Wang, X., Edwards, M., and Glindemann, D. (2005) Sources of matrix-bound phosphine in advanced wastewater treatment system. Chin Sci Bull 50:1274-1276.

Domagal-Goldman, S.D., Meadows, V.S., Claire, M.W., and Kasting, J.F. (2011) Using biogenic sulfur gases as remotely detectable biosignatures on anoxic planets. Astrobiology 11: 419-441.

Dua, R., Kumar, V., Sunkaria, A., and Gill, K. (2010) Altered glucose homeostasis in response to aluminium phosphide induced cellular oxygen deficit in rat. Indian J Exp Biol 48: 722-730.

Edwards, H.G.M. (2014) Will-o'-the-Wisp: an ancient mystery with extremophile origins? Philos Trans A Math Phys Eng Sci 372:20140206.

Eismann, F., Glindemann, D., Bergmannt, A., and Kuschk, P. (1997) Soils as source and sink of phosphine. Chemosphere 35:523-533.

Elm, J., Myllys, N., and Kurtén, T. (2017) Phosphoric acid-a potentially elusive participant in atmospheric new particle formation. Mol Phys 115:2168-2179.

Fall, R. and Copley, S.D. (2001) Bacterial sources and sinks of isoprene, a reactive atmospheric hydrocarbon. Environ $\mathrm{Mi}$ crobiol 2:123-130.

Feng, Z., Song, X., and Yu, Z. (2008a) Distribution characteristics of matrix-bound phosphine along the coast of China and possible environmental controls. Chemosphere 73:519-525.

Feng, Z., Song, X., and Yu, Z. (2008b) Seasonal and spatial distribution of matrix-bound phosphine and its relationship with the environment in the Changjiang River Estuary, China. Marine Poll Bull 56:1630-1636.

Figueroa, I.A. and Coates, J.D. (2017) Chapter 4-Microbial phosphite oxidation and its potential role in the global phosphorus and carbon cycles. In Advances in Applied Microbiology, edited by S. Sariaslani and G.M. Gadds, Academic Press, pp 93-117.

Fluck, E. (1973) The chemistry of phosphine. In Inorganic Chemistry. Fortschritte der Chemischen Forchung, vol 35/1. Springer, Berlin, Heidelberg.

Fu, M., Yu, Z., Lu, G., and Song, X. (2013) Henry's law constant for phosphine in seawater: determination and assessment of influencing factors. Chinese J Oceanol Limnol 31: 860-866.

Fuhrmann, J., Subramanian, V., Kojetin Douglas, J., and Thompson Paul, R. (2016) Activity-based profiling reveals a regulatory link between oxidative stress and protein arginine phosphorylation. Cell Chem Biol 23:967-977.

Gassmann, G. and Glindemann, D. (1993) Phosphane (PH3) in the biosphere. Angew Chem Int Ed Engl 32:761-763.

Glindemann, D., Stottmeister, U., and Bergmann, A. (1996) Free phosphine from the anaerobic biosphere. Environ Sci Poll Res 3:17-19.

Glindemann, D., Eismann, F., Bergmann, A., Kuschk, P., and Stottmeister, U. (1998) Phosphine by bio-corrosion of phosphide-rich iron. Environ Sci Poll Res 5:71-74. 
Glindemann, D., Edwards, M., Liu, J.-A., and Kuschk, P. (2005) Phosphine in soils, sludges, biogases and atmospheric implications-a review. Ecol Eng 24:457-463.

Glonek, T. (1994) 31P NMR in the analysis of extracted tissue phospholipids. In P-31 NMR Spectral Properties in Compound Characterization and Structural Analysis, edited by L.D. Quin and J.G. Verkade, VCH, New York, NY, pp 283-294.

Gorenstein, D.G. (editor) (1984) Phosphorus-31 chemical shifts: principles and empirical observations. In Phosphorous31 NMR, Elsevier, Amsterdam, The Netherlands, pp 7-36.

Gorenstein, D.G. (1994) 31-P NMR of nucleic acids. In Phosphorus-31 NMR Spectral Properties in Compound Characterization and Structural Analysis, edited by L.D. Quinn and J.G. Verkades, VCH, New York, pp 267-281.

Gribble, G. (2003) The diversity of naturally produced organohalogens. Chemosphere 52:289-297.

Gribble, G.W. (2009) Naturally Occurring Organohalogen Compounds-A Comprehensive Update. Springer Science \& Business Media, Vienna, Austria.

Grivet, J.-P., Delort, A.-M., and Portais, J.-C. (2003) NMR and microbiology: from physiology to metabolomics. Biochimie 85:823-840.

Gu, J., Gui, Y., Chen, L., Yuan, G., Lu, H.-Z., and Xu, X. (2013) Use of natural products as chemical library for drug discovery and network pharmacology. PLoS One 8:e62839.

Guarner, F. and Malagelada, J.-R. (2003) Gut flora in health and disease. Lancet 361:512-519.

Guenther, A.B., Jiang, X., Heald, C.L., Sakulyanontvittaya, T., Duhl, T., Emmons, L.K., and Wang, X. (2012) The Model of Emissions of Gases and Aerosols from Nature version 2.1 (MEGAN2.1): an extended and updated framework for modeling biogenic emissions. Geosci Model Dev 5:1471-1492.

Guillemin, J.C., Janati, T., and Lassalle, L. (1995) Photolysis of phosphine in the presence of acetylene and propyne, gas mixtures of planetary interest. Adv Space Res 16:85-92.

Hamilton, P.A. and Murrells, T.P. (1986) Mechanism for the chemiluminescence in oxygen-phosphorus system. J Phys Chem 90:182-185.

Han, S.-H., Zhuang, Y.-H., Liu, J.-A., and Glindemann, D. (2000) Phosphorus cycling through phosphine in paddy fields. Sci Total Environ 258:195-203.

Han, C., Geng, J., Hong, Y., Zhang, R., Gu, X., Wang, X., Gao, S., and Glindemann, D. (2011a) Free atmospheric phosphine concentrations and fluxes in different wetland ecosystems, China. Environ Poll 159:630-635.

Han, C., Geng, J., Zhang, J., Wang, X., and Gao, S. (2011b) Phosphine migration at the water-air interface in Lake Taihu, China. Chemosphere 82:935-939.

Han, C., Geng, J., Xie, X., Wang, X., Ren, H., and Gao, S. (2012) Determination of phosphite in a eutrophic freshwater lake by suppressed conductivity ion chromatography. Environ Sci Technol 46:10667-10674.

Hartley, S.B., Holmes, W.S., Jacques, J.K., Mole, M.F., and McCoubrey, J.C. (1963) Thermochemical properties of phosphorus compounds. Q Rev Chem Soc 17:204-223.

Harvey, E.N. (1940) Living Light. Princeton University Press, Princeton, NJ.

Herschy, B., Chang, S.J., Blake, R., Lepland, A., Abbott-Lyon, H., Sampson, J., Atlas, Z., Kee, T.P., and Pasek, M.A. (2018) Archean phosphorus liberation induced by iron redox geochemistry. Nat Commun 9:1346.

Hess, B.M., Xue, J., Markillie, L.M., Taylor, R.C., Wiley, H.S., Ahring, B.K., and Linggi, B. (2013) Coregulation of terpenoid pathway genes and prediction of isoprene produc- tion in Bacillus subtilis using transcriptomics. PLoS One 8: e66104.

Hobbs, S.K. and Bond, E.J. (1989) Response of Tribolium castaneum (Herbst) (Coleoptera: Tenebrionidae) to sublethal treatments with phosphine. J Stored Prod Res 25:137-146.

Hood, G.A. (1972) Zinc phosphide - a new look at an old rodenticide for field rodents. In 5th Vertebrate Pest Conference, University of Nebraska, Lincoln, Nebraska. Available online at https://digitalcommons.unl.edu/vpc5.

Horsman, G.P. and Zechel, D.L. (2017) Phosphonate biochemistry. Chem Rev 117:5704-5783.

Hsu, C.-H., Chi, B.-C., Liu, M.-Y., Li, J.-H., Chen, C.-J., and Chen, R.-Y. (2002) Phosphine-induced oxidative damage in rats: role of glutathione. Toxicology 179:1-8.

Ireland, M.W. (1926) The Medical Department of the United States Army in the World War, Volume XIV: Medical Aspects of Gas Warfare. Washington, DC: Government Printing Office: The Bureau of Mines, Pittsburgh, PA.

Iverson, W.P. (1968) Corrosion of iron and formation of iron phosphide by Desulfovibrio desulfuricans. Nature 217:1265-1267.

Iverson, W.P. (1974) Microbial corrosion of iron. In Microbial Iron Metabolism, Elsevier, Hoboken, NJ, USA. pp 475-513.

Jenkins, R.O., Morris, T.A., Craig, P.J., Ritchie, A.W., and Ostah, N. (2000) Phosphine generation by mixed- and monosepticcultures of anaerobic bacteria. Sci Total Environ 250:73-81.

Kallmeyer, J., Pockalny, R., Adhikari, R.R., Smith, D.C., and D'Hondt, S. (2012) Global distribution of microbial abundance and biomass in subseafloor sediment. Proc Natl Acad Sci U S A 109:16213-16216.

Kamer, P.C. and van Leeuwen, P.W. (2012) Phosphorus (III) Ligands in Homogeneous Catalysis: Design and Synthesis. John Wiley \& Sons, Hoboken, NJ, USA.

Kashi, K.P. and Chefurka, W. (1976) The effect of phosphine on the absorption and circular dichroic spectra of cytochrome $c$ and cytochrome oxidase. Pestic Biochem Physiol 6:350-362.

Kato, H., Nagayama, K., Abe, H., Kobayashi, R., and Ishihara, E. (1991) Isolation, structure and biological activity of trialaphos. Agric Biol Chem 55:1133-1134.

Katti, K.V., Gali, H., Smith, C.J., and Berning, D.E. (1999) Design and development of functionalized water-soluble phosphines: catalytic and biomedical implications. Acc Chem Res 32:9-17.

Knowles, C.J. and Bunch, A.W. (1986) Microbial cyanide metabolism. Adv Microb Physiol 27:73-111.

Kuroda, Y., Goto, T., Okamoto, M., Yamashita, M., Iguchi, E., Kohsaka, M., Aoki, H., and Imanaka, H. (1980a) FR-900137, a new antibiotic. I. Taxonomy and fermentation of the organism, and isolation and characterization of the antibiotic. J Antibiot (Tokyo) 33:272-279.

Kuroda, Y., Tanaka, H., Okamoto, M., Goto, T., Kohsaka, M., Aoki, H., and Imanaka, H. (1980b) FR-900137, a new antibiotic. II. Structure determination of FR-900137. J Antibiot (Tokyo) 33:280-283.

Lane, A.N. (2012) Principles of NMR for applications in metabolomics. In The Handbook of Metabolomics, edited by T.W.-M. Fan, A.N. Lane, and R.M. Higashi; Springer, New York, USA. pp 127-197.

Leitao, J., de Saint-Blanquat, G., and Bailly, J.-R. (1987) Action of phosphine on production of aflatoxins by various Aspergillus strains isolated from foodstuffs. Appl Environ Microbiol 53: 2328-2331.

Leitao, J., de Saint Blanquat, G., Bailly, J.-R., and Derache, R. (1990) Preventive measures for microflora and mycotoxin production in foodstuffs. Arch Environ Contam Toxicol 19:437-446. 
Linstrom, P.J. and Mallard, W.G. (2001) The NIST chemistry WebBook: A chemical data resource on the internet. J Chem Eng Data 46:1059-1063.

Logan, B.A., Monson, R.K., and Potosnak, M.J. (2000) Biochemistry and physiology of foliar isoprene production. Trends Plant Sci 5:477-481.

McElroy, C. and Day, B.J. (2016) Antioxidants as potential medical countermeasures for chemical warfare agents and toxic industrial chemicals. Biochem Pharmacol 100:1-11.

Mew, E.J., Padmanathan, P., Konradsen, F., Eddleston, M., Chang, S.-S., Phillips, M.R., and Gunnell, D. (2017) The global burden of fatal self-poisoning with pesticides 2006-15: systematic review. J Affect Disord 219:93-104.

Michael, R., Martin, K., Peter, W., Stetter, K.O., and Axel, Z. (1993) Secondary metabolites by chemical screening, 25. New cyclic polysulfides from hyperthermophilic archaea of the genus Thermococcus. Liebigs Ann Chem 1993:871-876.

Morton, S.C. and Edwards, M. (2005) Reduced phosphorus compounds in the environment. Crit Rev Environ Sci Technol 35:333-364.

Nagy, P. and Winterbourn, C.C. (2010) Chapter 6-Redox chemistry of biological thiols. In Advances in Molecular Toxicology, edited by J.C. Fishbeins, Elsevier, Amsterdam, The Netherlands, pp 183-222.

Nath, N.S., Bhattacharya, I., Tuck, A.G., Schlipalius, D.I., and Ebert, P.R. (2011) Mechanisms of phosphine toxicity. J Toxicol 2011:9.

Nauseef, W.M. (2007) How human neutrophils kill and degrade microbes: an integrated view. Immunol Rev 219:88-102.

OrgPrepDaily. (2008) This phosphine will get you fired. Available online at https://orgprepdaily.wordpress.com/2008/ 08/02/a-phosphine-that-will-get-you-fired

Pace, N.R. (2001) The universal nature of biochemistry. Proc Natl Acad Sci U S A 98:805-808.

Pasek, M.A. (2008) Rethinking early Earth phosphorus geochemistry. Proc Natl Acad Sci U S A 105:853-858.

Pasek, M.A. and Kee, T.P. (2011) On the origin of phosphorylated biomolecules. In Origins of Life: The Primal Self-Organization, edited by R. Egel, D.-H. Lankenau, and A.Y. Mulkidjanians, Springer Berlin Heidelberg, Berlin, Heidelberg, pp 57-84.

Pasek, M.A., Mousis, O., and Lunine, J.I. (2011) Phosphorus chemistry on Titan. Icarus 212:751-761.

Pasek, M.A., Harnmeijer, J.P., Buick, R., Gull, M., and Atlas, Z. (2013) Evidence for reactive reduced phosphorus species in the early Archean ocean. Proc Natl Acad Sci U S A 110: 10089-10094.

Pasek, M.A., Sampson, J.M., and Atlas, Z. (2014) Redox chemistry in the phosphorus biogeochemical cycle. Proc Natl Acad Sci U S A 111:15468-15473.

Pech, H., Vazquez, M.G., Van Buren, J., Foster, K.L., Shi, L., Salmassi, T.M., Ivey, M.M., and Pasek, M.A. (2011) Elucidating the redox cycle of environmental phosphorus using ion chromatography. J Chromatogr Sci 49:573-581.

Pedley, J.B. (2012) Thermochemical Data of Organic Compounds. Springer Science \& Business Media, London, U.K.

Perkins, M.W., Wong, B., Olivera, D., and Sciuto, A. (2015) Phosphine. In Hamilton \& Hardy's Industrial Toxicology, edited by R.D. Harbison, M.M. Bourgeois, and G.T. Johnson; John Wiley \& Sons, Hoboken, NJ, USA. pp 1295-1300.

Petkowski, J.J., Bains, W., and Seager, S. (2018) Natural products containing a nitrogen-sulfur bond. J Nat Prod 81: 423-446.

Petkowski, J.J., Bains, W., and Seager, S. (2019a) An apparent binary choice in biochemistry: mutual reactivity implies life chooses thiols or nitrogen-sulfur bonds, but not both. Astrobiology 19:000-000. doi:10.1089/2018.1831.

Petkowski, J.J., Bains, W., and Seager, S. (2019b) Natural products containing 'rare' organophosphorus functional groups. Molecules 24:866.

Pignatello, J.J., Oliveros, E., and MacKay, A. (2006) Advanced oxidation processes for organic contaminant destruction based on the Fenton reaction and related chemistry. Crit Rev Environ Sci Technol 36:1-84.

Pinault, N. and Bruce, D.W. (2003) Homogeneous catalysts based on water-soluble phosphines. Coordin Chem Rev 241: $1-25$.

Price, N.R. and Dance, S.J. (1983) Some biochemical aspects of phosphine action and resistance in three species of stored product beetles. Comp Biochem Physiol C Comp Pharmacol Toxicol 76:277-281.

Quistad, G.B., Sparks, S.E., and Casida, J.E. (2000) Chemical model for phosphine-induced lipid peroxidation. Pest Manag Sci 56:779-783.

Retgers, J. (1894) Über eine einfache Darstellungsweise des Phosphorwasserstoffes. (On basic characteristics of phosphine) Zeitschrift für anorganische und allgemeine Chemie 7: 265-266.

Robertson, H.E. and Boyer, P.D. (1956) Orthophosphite as a buffer for biological studies. Arch Biochem Biophys 62:396401.

Roels, J. and Verstraete, W. (2001) Biological formation of volatile phosphorus compounds. Bioresour Technol 79:243250.

Roels, J. and Verstraete, W. (2004) Occurrence and origin of phosphine in landfill gas. Sci Total Environ 327:185-196.

Roels, J., Huyghe, G., and Verstraete, W. (2005) Microbially mediated phosphine emission. Sci Total Environ 338:253265.

Ruth, J.H. (1986) Odor thresholds and irritation levels of several chemical substances: a review. Am Ind Hyg Assoc J 47: A142-A151.

Rutishauser, B.V. and Bachofen, R. (1999) Phosphine formation from sewage sludge cultures. Anaerobe 5:525-531.

Safo, M.K., Musayev, F.N., Wu, S.-H., Abraham, D.J., and Ko, T.-P. (2001) Structure of tetragonal crystals of human erythrocyte catalase. Acta Crystallogr D Biol Crystallogr 57:1-7.

Schmidt, O., Wüst, P.K., Hellmuth, S., Borst, K., Horn, M.A., and Drake, H.L. (2011) Novel [NiFe]- and [FeFe]hydrogenase gene transcripts indicative of active facultative aerobes and obligate anaerobes in earthworm gut contents. Appl Environ Microbiol 77:5842-5850.

Schulz, S. and Dickschat, J.S. (2007) Bacterial volatiles: the smell of small organisms. Nat Prod Rep 24:814-842.

Schwartz, A.W. (2006) Phosphorus in prebiotic chemistry. Philos Trans R Soc B Biol Sci 361:1743-1749.

Schwieterman, E.W., Kiang, N.Y., Parenteau, M.N., Harman, C.E., DasSarma, S., Fisher, T.M., Arney, G.N., Hartnett, H.E., Reinhard, C.T., Olson, S.L., Meadows, V.S., Cockell, C.S., Walker, S.I., Grenfell, J.L., Hegde, S., Rugheimer, S., Hu, R., and Lyons, T.W. (2018) Exoplanet biosignatures: a review of remotely detectable signs of life. Astrobiology 18: 663-708.

Sciuto, A.M., Wong, B.J., Martens, M.E., Hoard-Fruchey, H., and Perkins, M.W. (2016) Phosphine toxicity: a story of disrupted mitochondrial metabolism. Ann N Y Acad Sci 1374:41-51.

Seager, S. and Bains, W. (2015) The search for signs of life on exoplanets at the interface of chemistry and planetary science. Sci Adv 1:e1500047-e1500047. 
Seager, S., Schrenk, M., and Bains, W. (2012) An astrophysical view of earth-based metabolic biosignature gases. Astrobiology 12:61-82.

Seager, S., Bains, W., and Hu, R. (2013) A biomass-based model to estimate the plausibility of exoplanet biosignature gases. Astrophys J 775:104.

Seager, S., Bains, W., and Petkowski, J.J. (2016) Toward a list of molecules as potential biosignature gases for the search for life on exoplanets and applications to terrestrial biochemistry. Astrobiology 16:465-485.

Segura, A., Kasting, J.F., Meadows, V., Cohen, M., Scalo, J., Crisp, D., Butler, R.A., and Tinetti, G. (2005) Biosignatures from Earth-like planets around M dwarfs. Astrobiology 5: 706-725.

Seinfeld, J.H. and Pandis, S.N. (2016) Atmospheric Chemistry and Physics: From Air Pollution to Climate Change. John Wiley \& Sons, Hoboken, NJ, USA.

Shakoori, F.R., Feroz, A., and Riaz, T. (2016) Effect of sublethal doses of phosphine on macromolecular concentrations and metabolites of adult beetles of stored grain pest, Trogoderma granarium, previously exposed to phosphine. Pakistan $J$ Zool 48:583-588.

Sharkey, T.D. (1996) Isoprene synthesis by plants and animals. Endeavour 20:74-78.

Sharkey, T.D. and Loreto, F. (1993) Water stress, temperature, and light effects on the capacity for isoprene emission and photosynthesis of kudzu leaves. Oecologia 95:328-333.

Sharkey, T.D., Wiberley, A.E., and Donohue, A.R. (2008) Isoprene emission from plants: why and how. Ann Bot 101:5-18.

Sissons, J.W. (1989) Potential of probiotic organisms to prevent diarrhoea and promote digestion in farm animals - a review. J Sci Food Agric 49:1-13.

Sousa-Silva, C., Seager, S., Petkowski, J.J., Ranjan, S., Hu, R., Zhan, Z., and Bains, W. (2019) On phosphine as a biosignature gas in exoplanet atmospheres. Astrobiology 19:000-000.

Sun, F., Ding, Y., Ji, Q., Liang, Z., Deng, X., Wong, C.C.L., Yi, C., Zhang, L., Xie, S., Alvarez, S., Hicks, L.M., Luo, C., Jiang, H., Lan, L., and He, C. (2012) Protein cysteine phosphorylation of SarA/MgrA family transcriptional regulators mediates bacterial virulence and antibiotic resistance. Proc Natl Acad Sci U S A 109:15461-15466.

Sweetman, B. and Maclaren, J. (1966) The reduction of wool keratin by tertiary phosphines. Aust J Chem 19:2347-2354.

Thorger, L., Swantje, B., Keishi, I., Martin, R., and Christian, H. (2010) Closthioamide: an unprecedented polythioamide antibiotic from the strictly anaerobic bacterium Clostridium cellulolyticum. Angew Chem Int Ed Engl 122:2055-2057.

Valmas, N., Zuryn, S., and Ebert, P.R. (2008) Mitochondrial uncouplers act synergistically with the fumigant phosphine to disrupt mitochondrial membrane potential and cause cell death. Toxicology 252:33-39.

Vanelslander, B., Paul, C., Grueneberg, J., Prince, E.K., Gillard, J., Sabbe, K., Pohnert, G., and Vyverman, W. (2012) Daily bursts of biogenic cyanogen bromide $(\mathrm{BrCN})$ control biofilm formation around a marine benthic diatom. Proc Natl Acad Sci U S A 109:2412-2417.

Visscher, C., Lodders, K., and Fegley, B. (2006) Atmospheric chemistry in giant planets, brown dwarfs, and low-mass dwarf stars. II. Sulfur and phosphorus. Astrophys J 648:1181.

Wang, R. (2014) Gasotransmitters: growing pains and joys. Trends Biochem Sci 39:227-232.
Waritz, R.S. and Brown, R.M. (1975) Acute and subacute inhalation toxicities of phosphine, phenylphosphine and triphenylphosphine. Am Ind Hyg Assoc J 36:452-458.

Warthin, A.S. and Weller, C.V. (1919) The Medical Aspects of Mustard Gas Poisoning. C.V. Mosby Company, St. Louis, MO.

Westheimer, F.H. (1987) Why nature chose phosphates. Science 235:1173

Whitman, W.B., Coleman, D.C., and Wiebe, W.J. (1998) Prokaryotes: the unseen majority. Proc Natl Acad Sci U S A 95: 6578-6583.

Winget, P. and Clark, T. (2004) Enthalpies of formation from B3LYP calculations. J Comput Chem 25:725-733.

Yu, X., Geng, J., Ren, H., Chao, H., and Qiu, H. (2015) Determination of phosphite in a full-scale municipal wastewater treatment plant. Environ Sci 17:441-447.

Zhu, R., Kong, D., Sun, L., Geng, J., Wang, X., and Glindemann, D. (2006) Tropospheric phosphine and its sources in Coastal Antarctica. Environ Sci Technol 40:7656-7661.

Zhu, R., Wang, Q., Ding, W., Wang, C., Hou, L., and Ma, D. (2014) Penguins significantly increased phosphine formation and phosphorus contribution in maritime Antarctic soils. Sci Rep 4:7055.

Zuryn, S., Kuang, J., and Ebert, P. (2008) Mitochondrial modulation of phosphine toxicity and resistance in Caenorhabditis elegans. Toxicol Sci 102:179-186.

Żychowski, J. (2014) Conditions favoring the occurrence of ignis fatuus phenomenon over a mass grave in Niepołomice (S Poland). Proc Soc Behav Sci 120:347-355.

Address correspondence to: William Bains Rufus Scientific 37 The Moor, Melbourn Royston, Herts SG8 6ED United Kingdom

E-mail: bains@mit.edu

Submitted 16 September 2018

Accepted 13 February 2019 Associate Editor: David Deamer

$\begin{aligned} & \quad \text { Abbreviations Used } \\ & \mathrm{ADP}=\text { adenosine diphosphate } \\ & \mathrm{ATP}=\text { adenosine triphosphate } \\ & \mathrm{CWA}=\text { chemical warfare agent } \\ & \mathrm{C}_{5} \mathrm{H}_{8}=\text { isoprene } \\ & \mathrm{H}_{2} \mathrm{O}_{2}=\text { hydrogen peroxide } \\ & \mathrm{MP}=\text { methylphosphine } \\ & \mathrm{NADH}=\text { nicotinamide adenine dinucleotide (reduced form) } \\ & \mathrm{O}_{2}=\text { oxygen } \\ & \mathrm{P}=\text { phosphine } \\ & \mathrm{PH}=\text { phosphine gas } \\ & \mathrm{PP}=\text { phenylphosphine } \\ & \mathrm{ROS}=\text { reactive oxygen species } \\ & \text { tOP }=\text { trioctylphosphine }\end{aligned}$




\section{Appendix A. Pyrophoricity of Trivalent Phosphorus Compounds}

All phosphines are highly inflammable, but only some spontaneously burst into flames at room temperature in air. As summarized in the main text, pure phosphine is not spontaneously flammable, diphosphine is. An extensive search of the literature did not identify any systematic survey of the spontaneous inflammability of other phosphines, so we searched the catalog of Sigma-Aldrich (https:// www.sigmaaldrich.com), a well-known chemical supplier, for phosphines and related compounds, and then searched their safety data sheets (SDSs) for statements that they were spontaneously inflammable. The results are compiled in Appendix Table A1.
In general, phosphines can be spontaneously inflammable; phosphinites and phosphite esters are not. We note that the SDSs for tri-alkylphosphite esters state that they react violently with water, and so they are unlikely to be products of metabolism. There is no very clear pattern to whether a phosphine derivative is spontaneously inflammable or not. However, most alkyl phosphines in this list are spontaneously inflammable in air.

We note that this does not necessarily mean that relatively small amounts of the chemicals concerned could ignite methane if the gas mixture was mixed with air. The ignition below is for pure compounds.

Boiling point is estimated to give an indication of volatility: compounds with boiling points above $\sim 50^{\circ} \mathrm{C}$ are going to have a relatively low vapor pressure over ambient (cold) water, and hence have only trace presence in the atmosphere.

Appendix Table A1. List of Some Low-Molecular-Weight Phosphines from the Sigma-Aldrich Catalog, and Whether They Are Spontaneously Inflammable, as Listed in the Safety Data Sheets for Those Compounds

\begin{tabular}{|c|c|c|c|c|}
\hline Name & Structure & $\begin{array}{l}\text { Sigma-Aldrich } \\
\text { catalog number }\end{array}$ & $\begin{array}{c}\text { Spontaneously } \\
\text { inflammable? }\end{array}$ & $\begin{array}{r}\text { Estimated } \\
\text { boiling point } \\
\text { (from EpiSuit }\end{array}$ \\
\hline \multicolumn{5}{|l|}{ Phosphine } \\
\hline Phosphine & & 295647 & No & $-87.7 *$ \\
\hline \multicolumn{5}{|l|}{ Mono- and di-alkyl phosphines } \\
\hline Di-tert-butylphosphine & & 62719 & Yes & 112.28 \\
\hline Phenylphosphine & & 674389 & Yes & 159.97 \\
\hline Dicyclopentylphosphine & & 682918 & Yes & 213.12 \\
\hline Diphenyl phosphine & & 252964 & Yes & 279.92 \\
\hline \multicolumn{5}{|l|}{ Tri-alkylphosphines } \\
\hline Trimethyl phosphine & & 323322 & No & $38 *$ \\
\hline Methylditertbutylphosphine & & 642629 & Yes & 136.29 \\
\hline Triisopropylphosphine & & 377309 & Yes & 140.57 \\
\hline
\end{tabular}




\begin{tabular}{|c|c|c|c|c|}
\hline Name & Structure & $\begin{array}{l}\text { Sigma-Aldrich } \\
\text { catalog number }\end{array}$ & $\begin{array}{l}\text { Spontaneously } \\
\text { inflammable? }\end{array}$ & $\begin{array}{c}\text { Estimated } \\
\text { boiling point }{ }^{\circ} \mathrm{C} \\
\text { (from EpiSuite) }\end{array}$ \\
\hline Tert-butyldiisopropylphosphine & & 639346 & Yes & 153.96 \\
\hline Tributylphosphine & & T49484 & Yes & 238.06 \\
\hline Dicyclohexyl(ethyl)phosphine & & 695920 & Yes & 286.60 \\
\hline Bis(dimethylphosphino)methane & & 592684 & Yes & 129.74 \\
\hline 1,2-Bis(dimethylphosphino)ethane & & 61939 & No & 152.17 \\
\hline $\begin{array}{l}\text { Phosphonates and phosphinates } \\
\text { Trimethylphosphite }\end{array}$ & & 240907 & No & $111.50^{*}$ \\
\hline Triethylphosphite & & T61204 & No & $157.90^{*}$ \\
\hline Methyl diphenylphosphinite & & 149497 & No & 310.97 \\
\hline Ethyl diphenylphosphinite & & 149489 & No & 324.51 \\
\hline Tris(hydroxymethyl)phosphine & & 177881 & No & (solid) \\
\hline
\end{tabular}

Many substituted phosphines react violently with oxygen and are flammable. Boiling points are actual values (marked as *) or estimates from the EpiSuite software (https://www.epa.gov/tsca-screening-tools). Sigma-Aldrich catalog numbers are included for ease of reference. 